\title{
Switch in photocatalytic reaction selectivity: the effect of oxygen partial pressure on carbon-carbon bond dissociation over hydroxylated $\mathrm{TiO}_{2}(110)$ surfaces.
}

\author{
G. Harrison ${ }^{2}$, K. Katsiev ${ }^{1}$, Y. Alsalik ${ }^{1}$, G. Thornton*2, and H. Idriss ${ }^{1,2 *}$; \\ ${ }^{1}$ Fundamental Catalysis, SABIC-CRD at KAUST, Thuwal, Saudi Arabia and ${ }^{2}$ Department of \\ Chemistry and the London Centre for Nanotechnology, University College London, London WC1H \\ OAJ, UK; \\ *Email: idrissh@sabic.com and h.idriss@ucl.ac.uk \\ *Email: g.thornton@ucl.ac.uk
}

\section{Abstract}

Photocatalytic oxidation of ethanol over rutile $\mathrm{TiO}_{2}(110)$ in the presence of $\mathrm{O}_{2}$ have been studied with scanning tunneling microscopy and on-line mass spectrometry to elucidate the reaction mechanisms. The $\mathrm{O}_{2}$ partial pressure has a direct impact on $\mathrm{C}-\mathrm{C}$ bond cleavage, resulting in a shift of selectivity in gas phase products from acetaldehyde (dehydrogenation) to methyl radicals ( $C-C$ bond dissociation) with increasing pressure. This differs from the behavior of anatase $\mathrm{TiO}_{2}(101)$ single crystal, where at all investigated pressures negligible $\mathrm{C}-\mathrm{C}$ bond dissociation occurs. The prevalence of the methyl radical species at high oxygen pressures is correlated with an increase in the surface population of an adsorbed species bound to Ti $i_{5 c}$ after the reaction, which are identified as formate moieties. Parallel XPS C1s, Ti2 $p$ and $O 1 s$ further confirmed the assignment of surface population, by STM, to ethoxides at 300K, in dark conditions ( $\mathrm{Cls}$ at 286.7 and $285.4 \mathrm{eV}$ attributed to $-\mathrm{CH}_{2} \mathrm{O}$ - and $-\mathrm{CH}_{3}$ groups respectively). After photoreaction, a large fraction of the surface was covered by formates (XPS C1 at $289.7 \mathrm{eV}$ ). This also correlated with the STM assignment where species spaced by $6 A$ along the [001] direction and with a height of ca. A attributed to formates. Moreover the profile for $\mathrm{CH}_{3}$ radical desorption in the gas phase as a function $\mathrm{O}_{2}$ partial pressures correlated with the increasing surface population of formates. Analysis of the rate of methyl radical formation reveals fast and slow regimes, with photoreaction cross-sections between $10^{-17} \mathrm{~cm}^{2}$ and $10^{-19} \mathrm{~cm}^{2}$. The parallel channel of acetaldehyde production has a nonvarying cross-section of ca. $2 \times 10^{-19} \mathrm{~cm}^{2}$. A schematic description of the two different reaction channels (dehydrogenation and $C-C$ bond dissociation) is given and discussed. 


\section{Introduction}

Photocatalysis, a process whereby a semiconductor is activated by photons to conduct a chemical reaction, has potential to replace thermal catalytic reactions and therefore provides an alternative to energy-intensive fossil fuel based catalysis. Two main reactions are currently being pursued in photocatalysis. The first, $\mathrm{H}_{2}$ from water, was demonstrated by Fujishima and Honda using a $\mathrm{TiO}_{2}$ photocatalyst.[1] The second is the conversion of biofuel to valuable compounds. These two broadly-defined reactions are interconnected since hydrogen can be synthesized from oxygen containing compounds in the presence of water, for example. A successful commercial catalyst would be composed of multiple semiconductors to harvest the largest possible fraction of sunlight. $\mathrm{TiO}_{2}$, probably the most active and stable single component photocatalyst and the most understood metal oxide can be used as a prototype for fundamental investigations of the numerous catalytic steps under photo-irradiation. In this work, we focus on the reaction of ethanol (as an example of a $\mathrm{C}-\mathrm{C}$ bond containing compound made from renewables) on the surface of hydroxylated rutile (110) $\mathrm{TiO}_{2}$. The ethanol redox potential relative to the valence band of $\mathrm{TiO}_{2}$ is energetically favorable and fits within the electron transfer scheme of Marcus Theory.[2]

Despite the large number of studies of the photocatalytic reactions of oxygen containing compounds on $\mathrm{TiO}_{2}$, a detailed understanding of the reaction mechanism is still lacking.[3] The aim here is to use a well-defined single crystalline surface of $\mathrm{TiO}_{2}$ to achieve a fundamental insight into the photoreaction selectivity and associated active sites, from which simple but reasonably accurate kinetic parameters can be extracted. A hydroxylated surface is chosen for study because it represents the likely termination of (110) facets of the polycrystalline material at room temperature. In polycrystalline materials the rutile phase is often a component ( $20 \%$ of P25 for example) resulting in "possible" photocatalytic synergy with anatase.[4] The rutile crystal phase has also been shown in certain cases to possess a higher photo-oxidation activity than the anatase phase.[2-4]

The (110) termination of rutile $\mathrm{TiO}_{2}$ has the lowest surface energy and is expected to contribute substantially to the photocatalytic activity of the material. As shown by quantitative surface diffraction,[5-7] and many Scanning Tunneling Microscopy (STM) studies, this surface is composed of alternating rows of five-fold coordinated $\mathrm{Ti}^{4+}$ cations and bridging two-fold coordinated $\mathrm{O}^{2-}$ anions, separated by $6.5 \AA$ in the $[1 \overline{1} 0]$ direction. The spacing between the $\mathrm{Ti}^{4+}$ cations in the [001] direction is $2.96 \AA$. A filled ball model of the (110) surface with ethanol and formate adsorbed in different coordination modes is presented in Figure 1. 


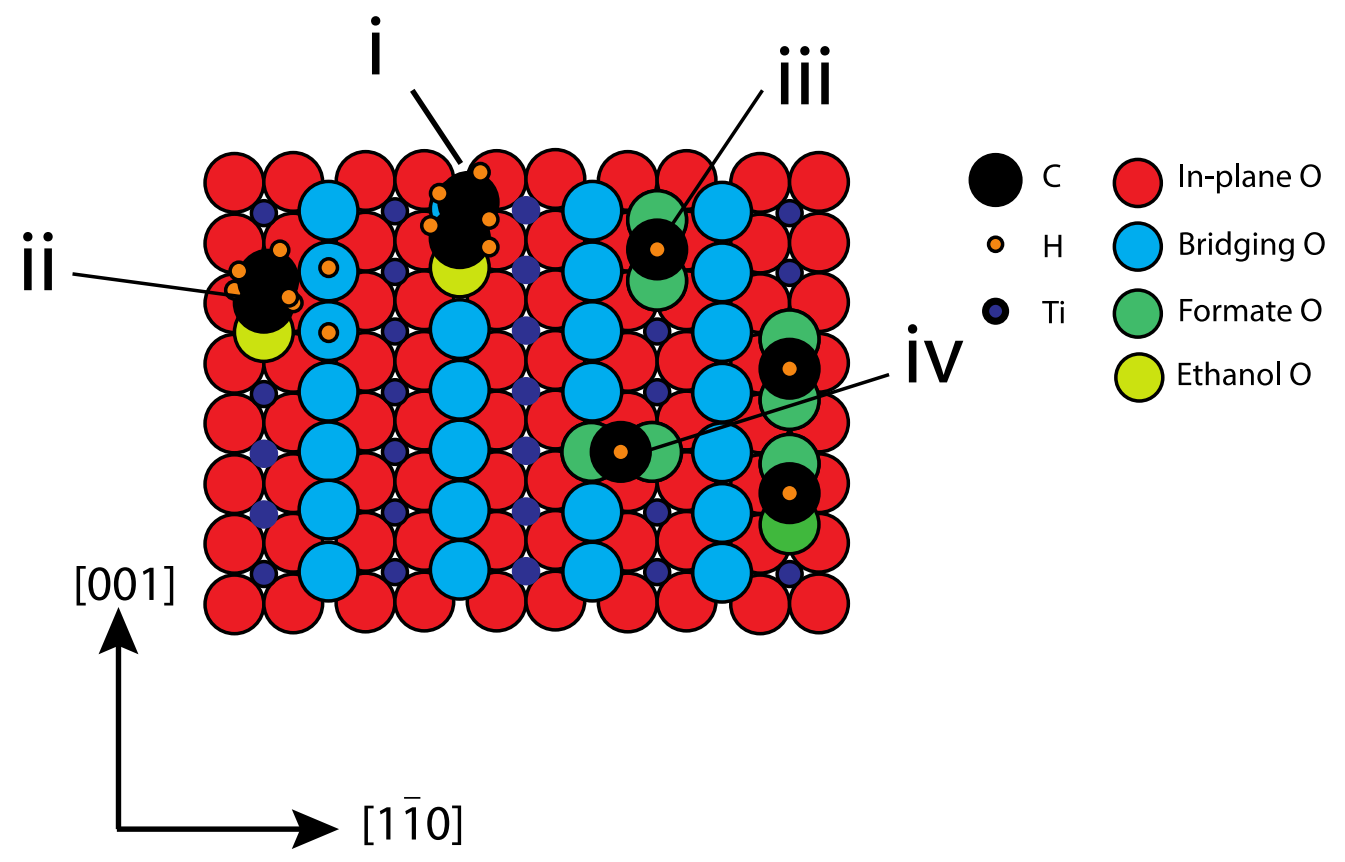

Figure 1: A space filling model of rutile $\mathrm{TiO}_{2}(110)-(1 \times 1)$, small dark blue spheres: $\mathrm{Ti}^{4+}{ }_{5 c}$, large light blue spheres: $\mathrm{O}^{2-}{ }_{2 c}$, large red spheres: $\mathrm{O}^{2-}{ }_{3 \mathrm{c}}$. The structures of ethanol and formates on the surface are also shown. These are: (i) Ethanol on a $\mathrm{V}_{\mathrm{Obr}}$; (ii) ethanol on $\mathrm{Ti}^{4+}{ }_{5 c}$; (iii) bidentate formate on adjacent $\mathrm{Ti}_{5 \mathrm{c}}$ along the [100] direction; (iv) bidentate formate on a $\mathrm{Ti}_{5 \mathrm{c}}$ and an adjacent $\mathrm{V}_{\mathrm{obr}}$ along the [1ī0] direction. Two $\mathrm{O}_{\mathrm{br}} \mathrm{H}$ are shown. The azimuths with respect to the rutile $\mathrm{TiO}_{2}(110)$ surface are shown.

Ethanol adsorption and its photo-reaction have been studied on polycrystalline $\mathrm{TiO}_{2}$ samples.[8-13] Surface science studies of the adsorption of alcohols on single crystal $\mathrm{TiO}_{2}$ include the rutile $\mathrm{TiO}_{2}(110)$ and $\{011\}$ - and $\{114\}$-facetted $\mathrm{TiO}_{2}(001)$ single crystal terminations, $[14,15]$ with the (110) termination receiving most of the attention.[16] Limited studies have been conducted on the surfaces of anatase single crystals with only two alcohols: methanol[17,18] and ethanol on the (101) surface.[19]

Ethanol adsorption and reaction are sensitive to the presence of oxygen defects on the rutile $\mathrm{TiO}_{2}(110)$ surface. STM studies have indicated that in the presence of bridging oxygen vacancies $\left(\mathrm{V}_{\mathrm{Obr}}\right)$, bright features arise between the $\mathrm{Ti}_{5 \mathrm{c}}$ rows following adsorption, which are assigned to EtO- on $V_{\text {obr }}$ species (Figure 1 i). These are not observed on (nearly) stoichiometric surfaces.[20-22] In addition, STM results indicate that ethanol is also bound to the $\mathrm{Ti}_{5 \mathrm{c}}$, arranged in rows aligned along the [001] directions forming a partial monolayer at room temperature (Figure 1 ii).[21] This is in accordance with the $0.5 \mathrm{ML}$ room temperature saturation coverage of ethanol, extracted from X-ray photoelectron spectroscopy (XPS) Ti 2 p and O 1s attenuation and consistent with the van der Waal radius ( $5 \AA$ ) of the ethanol molecule, preventing stable adsorption at two adjacent [001] direction $\mathrm{Ti}_{5 \mathrm{c}}$ sites.[23] Temperature Programmed Desorption (TPD) of ethanol adsorbed on rutile $\mathrm{TiO}_{2}(110)$ has also been studied,[24-27] revealing the desorption of multilayer ethanol (143 K), a second layer (168 
K), and the broad peak of the first monolayer at (295) K.[28] Ethanol desorption has also been observed from room temperature saturated $\mathrm{TiO}_{2}(110)$ at: $370 \mathrm{~K}[29], 300-450 \mathrm{~K}[30] 400 \mathrm{~K}[31]$. A minor ethanol desorption peak is also observed above $600 \mathrm{~K}[11,29]$, attributed based on the initial work of Gambel et al.[24] to re-combinative desorption from ethoxides adsorbed on $\mathrm{V}_{\text {Obr. }}$.

It has also been demonstrated that ethanol can adsorb via $\mathrm{O}-\mathrm{H}$ bond dissociation on the $\mathrm{Ti}^{4+}{ }_{5 \mathrm{c}}$, leading to the chemisorbed surface bound $\mathrm{CH}_{3} \mathrm{CH}_{2} \mathrm{O}(\mathrm{a})$ and $\mathrm{O}_{\mathrm{br}} \mathrm{H}$ moieties based on the $\mathrm{C}$ 1s XPS signal.[23] Further evidence is provided by DFT computational studies that indicate the greater stability of the dissociated adsorbate, with a binding energy of $80 \mathrm{~kJ} \mathrm{~mol}^{-1}$ compared with $65 \mathrm{~kJ} \mathrm{~mol}^{-1}$ for molecular adsorption onto $\mathrm{Ti}_{5 \mathrm{c}}$ sites.[29, 30, 32]

The photo-oxidation of ethanol occurs in multiple steps on $\mathrm{TiO}_{2}$. The first one results in the formation of acetaldehyde upon dehydrogenation [2,12,22,29,31]. Acetaldehyde then further react to, ultimately, give $\mathrm{CO}_{2}$ and water. This reaction, that requires the presence of gas phase oxygen and light, occurs via a methyl radical ejection from adsorbed acetaldehyde as probed by mass spectrometry by Kershis and White [33] and Zehr and Henderson [34]. Once the methyl radical is ejected, the remaining species are postulated to be formates $(\mathrm{HCOO}(\mathrm{a}))$. The overall reaction is written as $\left(\mathrm{CH}_{3} \mathrm{CHO}(\mathrm{a})+[\mathrm{O}]+1 \mathrm{~h} \rightarrow \mathrm{CH}_{3}\right.$ radical $+\mathrm{HCOO}(\mathrm{a})$; where $[\mathrm{O}]$ is an $\left.\mathrm{O}^{2-}\right)$. Other studies have also detected methyl radicals from other methyl containing compounds such as acetone [35] and acetic acid, the latter is formed by the so called "Photo-Kolbe reaction" [36].

Carboxylates (formed upon oxidation) have been identified over poly-crystalline $\mathrm{TiO}_{2}$ by many researchers.[37-39] Formic acid, the simplest carboxylic acid, has been extensively studied on rutile $\mathrm{TiO}_{2}(110)$.[16,40] STM[41-43] data revealed a $(2 \times 1)$ overlayer resulting from its dissociative adsorption on pairs of $\mathrm{Ti}_{5 \mathrm{c}}$ in the [001] direction (Figure 1 iii). A number of other bonding environments on $\mathrm{TiO}_{2}(110)$ were also observed by STM, including coordination to a $\mathrm{Ti}_{5 \mathrm{c}}$ and filling of an oxygen vacancy (Figure 1 iv).[44] Mattsson et al.[45] used Reflection Absorption Infra-Red Spectroscopy (RAIRS) to demonstrate the presence of another mode of coordination with a monodentate $\mathrm{Ti}_{5 \mathrm{c}} \mathrm{O}$-coordination normal to the [001] azimuth where an adjacent $\mathrm{OH}$ forms a hydrogen bond. Water reacting with the surface (healing the oxygen vacancies) has also been shown to lead to other formate adsorption types.[16] In addition to STM, these structures have been determined by photoelectron diffraction,[16], NEXAFS[44] as well as by infra-red spectroscopy.[45,46] A significant relaxation of the surface Ti and O positions occurs; these studies were corroborated by theoretical studies.[47,48] Similar results are obtained at the interface with liquid acetic acid.[49]

From the above description of the reaction of this simplest $\mathrm{C}-\mathrm{C}$ bond containing primary alcohol over the surface of $\mathrm{TiO}_{2}$ in the presence of light many questions remain unanswered for the catalytic steps to be understood. Among them are the following two; (1) what is the effect of oxygen partial pressure on the photocatalytic reaction selectivity (dehydrogenation to acetaldehyde versus C$\mathrm{C}$ bond dissociation) and (2) if indeed fragmentation occurs via the ejection of a methyl radical then 
the profile (build up) of surface formates should mirror that of gas phase $\mathrm{CH}_{3}$ radicals. In this work, we have studied the UV-induced photoreaction of ethanol adsorbed on the rutile $\mathrm{TiO}_{2}(110)$ surface at room temperature. Online-mass spectrometry (MS) was employed to monitor the photo-desorption products, while STM and XPS were used to identify the adsorbed species and stable photoreaction intermediates remaining on the surface after illumination.

\section{Experimental}

The mass spectrometry and STM measurements were conducted in a UHV system operating at a base pressure of $1 \times 10^{-10} \mathrm{mbar}$ at SABIC-CRD. The system is equipped with an Aahrus $15 \mathrm{HT}$ variable temperature STM by SPECS and a HALO 301 residual gas analyzer (RGA). In addition, the system is fitted with a sputter gun and individual oxygen, argon and ethanol lines. For photoreaction measurements, the RGA was mounted in a Pyrex shroud with a $5 \mathrm{~mm}$ aperture to enhance product detection from the surface. During mass spectrometry (with or without UV illumination), the sample was positioned $1 \mathrm{~mm}$ or less away from the shroud opening. A $300 \mathrm{~W}$ MAS 303 Asahi Spectra Xe lamp was used for the UV light source. The filtered Xenon UV light was delivered through a fiber optic focusing assembly, with an illumination power close to $10 \mathrm{mWcm}^{-2}$ being measured for wavelengths close to $310-400 \mathrm{~nm}$. The power output on the sample equates to a flux of $\sim 1.84 \times 10^{16}$ photons $\mathrm{s}^{-1} \mathrm{~cm}^{-2}$.

The rutile (110) single crystal (Matek; $10 \times 5 \times 2 \mathrm{~mm}^{3}$ ) was attached to a Ta plate using spotwelded Ta foil. The crystal was sputtered $(10$ mins, $1 \mathrm{kV}, 5 \mu \mathrm{A}$ sample current at Ar pressure of ca. 2 $\times 10^{-5}$ mbar) and annealed to ca. $1000 \mathrm{~K}$ until a flat morphology was determined by STM. The sample temperature was monitored with a Sirius pyrometer (Process Sensors) and a calibrated thermocouple (type K).

The same STM tip was used throughout the measurements, made by electrochemically etching a tungsten wire $(0.20 \mathrm{~mm}$ diameter $)$. It was conditioned to obtain atomic resolution images of $\mathrm{TiO}_{2}(110)$ by repetitive $+5 \mathrm{~V}$ sample bias pulses.

The cleanliness of the sample was monitored by STM. The $\mathrm{TiO}_{2}(110)$ surface was deemed clean when bright rows of $\mathrm{Ti}_{5 \mathrm{c}}$ were visible with characteristic steps, with a unit cell of $\left(3 \times 6.5 \AA^{2}\right)$ and minimal coverage of large contaminants. Calibration of the STM images employed the dimension of the (110) unit cell and step height (3.2 $\AA$ ). Within this study, a monolayer (ML) is defined with respect to $\mathrm{Ti}_{5 \mathrm{c}}$ sites on an ideal planar surface, which corresponds to $5.2 \times 10^{14} \mathrm{Ti}$ atoms $\mathrm{cm}^{-2}$.

Ethanol (VWR; 99.85\%) was contained within a glass-metal vial attached to a gas line back filling a UHV precision leak valve. The ethanol was purified by standard freeze-pump-thaw cycles and monitored by the RGA. Exposures of ethanol in this work are quoted in Langmuir (L) (1 Langmuir = $\left.1.33 \times 10^{-6} \mathrm{mbar} \mathrm{s}\right)$, where the uncompensated chamber pressure was $1 \times 10^{-9} \mathrm{mbar}$. Oxygen $(99.9 \%)$ 
was leaked into the chamber via the same gas line, with a UHV precision leak valve to achieve pressures in the range $8 \times 10^{-9}-3 \times 10^{-7}$ mbar. The gas line containing both the glass-metal vial of ethanol and $\mathrm{O}_{2}$ cylinder was pumped by a roughing pump at pressure of ca. $10^{-3}$ torr. In the case of STM, imaging upon formic acid adsorption the crystal was cleaned by Ar ions sputtering and annealing to ca. $773 \mathrm{~K}$ (30 minutes) cycles until a clean surface is obtained. Formic acid was then dosed to the surface $\left(5 \times 10^{-8}\right.$ torr for 60 seconds $\left.=3 \mathrm{~L}\right)$ in the pre-chamber, pumped down to ca. $10^{-9}$ mbar before being transferred to the STM chamber for data acquisition.

Photoreactions were conducted as follows. Upon ethanol adsorption, the surface was exposed to $\mathrm{O}_{2}$ for an initial time of $120 \mathrm{~s}$ at the designated $\mathrm{O}_{2}$ pressure to obtain a stable flat baseline at which point the UV light shutter was opened, then maintained at constant pressure for the photoreaction duration (180 s). Four masses (m/e 29, 15, 44, 31) were monitored during 1 hour of degassing, achieving a $1 \times 10^{-9}$ mbar pressure and rising to $2 \times 10^{-9}$ mbar during the photoreaction.

The main contributor to $\mathrm{m} / \mathrm{e} 29$ was attributed to acetaldehyde as the $\mathrm{CHO}$ fragmentation product, after removal of the minor (10\%) ethanol fragment component, and background subtraction, $\left(\mathrm{m} / \mathrm{e} 29(\mathrm{CHO})=\mathrm{m} / \mathrm{e} 29-\mathrm{m} / \mathrm{e} 31 \times 0.1-\mathrm{m} / \mathrm{e} 29\right.$ clean $\left.\mathrm{TiO}_{2}(110)\right)$. The m/e 15 attributed to the $\mathrm{CH}_{3}$ • radical was computed after removal of the $\mathrm{CH}_{3}$ - contribution from the acetaldehyde fragment $(15 \mathrm{~m} / \mathrm{e} \mathrm{CH}$ radical $=15 \mathrm{~m} / \mathrm{e}-0.25 \times 29 \mathrm{~m} / \mathrm{e})$.

XPS measurements were performed in a separate UHV system, with a base pressure of $5 \times 10^{-}$ ${ }^{10}$ mbar, equipped with SPECS XR50 dual anode X-ray source (Mg k $\alpha$ was utilized), and Scienta R3000 hemispherical electrostatic energy analyzer (at SABIC-CRD). Also attached to the chamber was a sputter gun, separate oxygen, argon and ethanol gas lines fitted with precision UHV leak valves. A transparent standard UHV port window was positioned for UV illumination. The single crystal was cleaned with cycles of Ar ions sputtering and annealing at $773 \mathrm{~K}$ ( 30 minutes) until a clean surface and a Ti2p sharp line with a FWHM of $1.2 \mathrm{eV}$ or below are obtained. Photocatalytic reactions were conducted with the same Xenon lamp, used for STM studies, at $100 \%$ power producing ca. $10^{16}$ photons $\mathrm{cm}^{-2} \mathrm{~s}^{-1}$ in the $320-400 \mathrm{~nm}$ range (as in the case of STM). The crystal was then exposed to $1 \mathrm{x}$ $10^{-7}$ torr of ethanol at $240 \mathrm{~K}$ for 3 minutes $(18 \mathrm{~L})$, then $\mathrm{C} 1 \mathrm{~s}$, Ti2p and $\mathrm{O} 1 \mathrm{~s}$ lines were collected. This was followed by heating to $240,250,260$ and $300 \mathrm{~K}$ incrementally. At each temperature, the same XPS lines were collected. The photocatalytic reaction was conducted upon exposing a fresh surface to saturation coverage of ethanol following the same method. The chamber was then pumped down for one hour until reaching a base pressure of ca. $10^{-9} \mathrm{mbar}$. The surface was then exposed to UV light at $5 \times 10^{-7}$ mbar of $\mathrm{O}_{2}$ for 30 minutes. Subsequently, the chamber was pumped down to ca. $10^{-9}$ mbar before XPS data collection. 


\section{Results}

\section{Clean and Ethanol/Rutile $\mathrm{TiO}_{2}(110)$}

An STM image of the as-prepared rutile $\mathrm{TiO}_{2}(110)$ is shown in Figure 2A, evidencing the presence of a clean unreconstructed surface with $100 \AA$ wide terraces. The bright rows running in the [001] direction arise from $\mathrm{Ti}_{5 c}{ }^{4+}$ ions separated by about $3 \AA$ along [001]. After 1 hour in the residual vacuum of $2 \times 10^{-10}$ mbar the surface was fully hydroxylated with no $\mathrm{O}_{\text {vac }}$ present. The bright features lying between the bright rows arise from bridging hydroxyls $\left(\mathrm{O}_{\mathrm{br}} \mathrm{H}\right)$, which appear at a height of $\sim 0.5$ $\AA$.[26] Higher resolution images (Figure 2B, 2C) $\left(90 \times 90 \AA^{2}\right)$ evidence two tip-dependent imaging modes; the second imaging mode (Figure 2C) was found to provide better images of the ethanolinduced adsorbates. Figure 3A shows an STM image $\left(250 \times 220 \AA^{2}\right)$ recorded following exposure to 13.5 $\mathrm{L}$ of ethanol $\left(180 \mathrm{~s}, 1 \times 10^{-7} \mathrm{mbar}\right)$ at $\sim 300 \mathrm{~K}$. The adsorbate features correspond to ca. $0.06 \mathrm{ML}$ coverage of ethanol and/or ethoxy species that decorate terraces and step edges. A high resolution image $\left(80 \times 80 \AA^{2}\right)$ is shown in Figure 3B, where adsorbates with heights of $1.7 \AA$ and $0.8 \AA$ can be resolved. The former lies on top of the Ti rows (pink box), whereas the latter lies on the $\mathrm{O}_{2 \mathrm{c}}$ rows (blue box), by reference to images recorded in the contrast mode evidenced in Figure 2B. In addition, bright features also of $\sim 1.7 \AA$ height (yellow box) decorate the step edges of the surface, aligned with the upper terrace $\mathrm{O}_{2 c}$ rows. The latter features are, as previously assigned, consistent with EtOs, where EtOH have dissociated with the scission of the O-H bond with the stable step edge oxygen vacancies $\left(V_{0}\right)$ along the $<1 \overline{1} 1>$ upper step edges. Such a reaction has been studied by Martinez et al.[26]

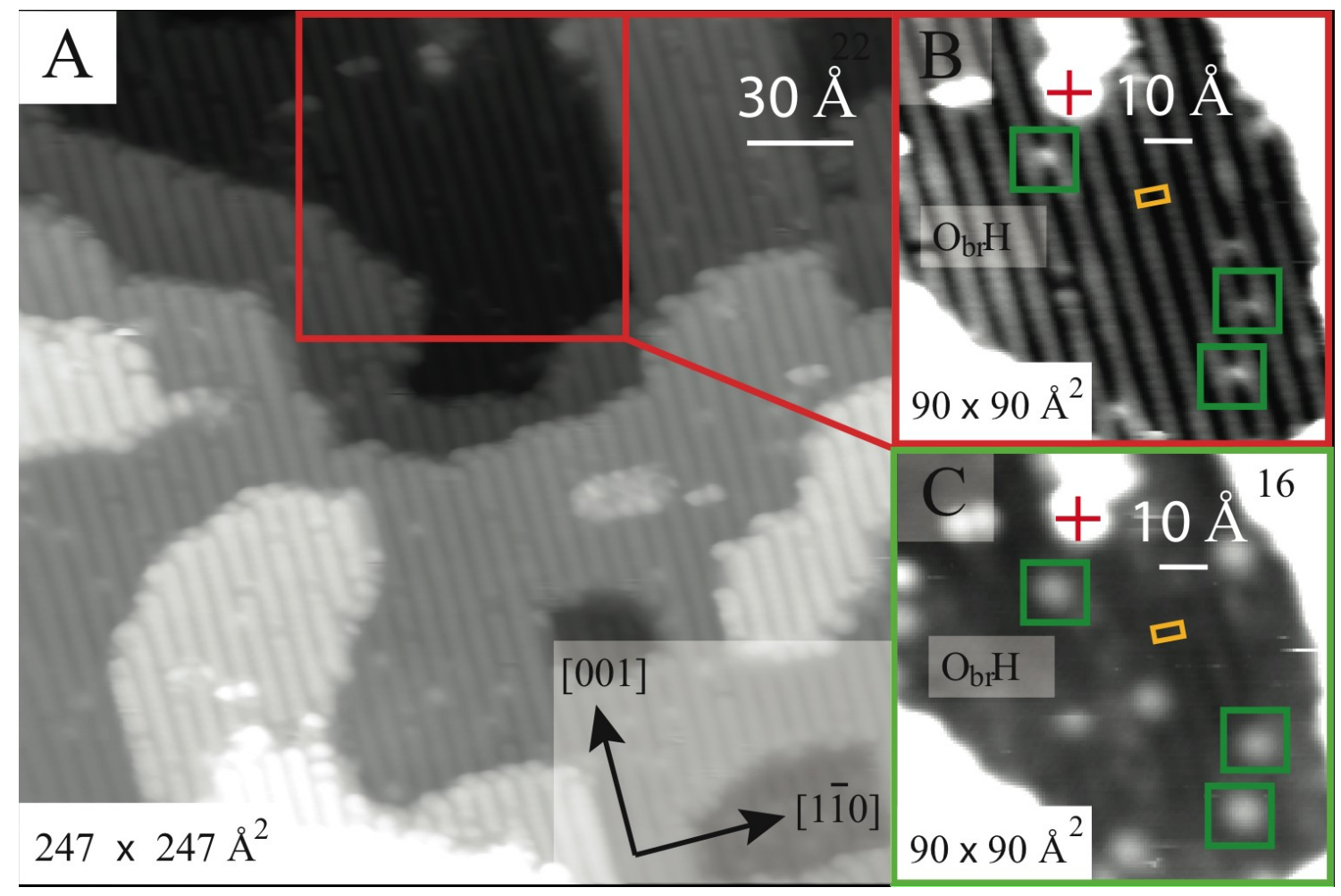


Figure 2: $300 \mathrm{~K}$ STM images (+1.65 V sample bias, $0.1 \mathrm{nA}$ ) of rutile $\mathrm{TiO}_{2}(110)$. (A) $247 \times 247 \AA^{2}$ of the clean- $(1 \times 1)$ surface. $\mathrm{O}_{\mathrm{br}} \mathrm{H}$ species (ca. $\left.0.01 \mathrm{ML}\right)$ lie on the $\mathrm{O}_{2 \mathrm{c}}$ rows. A red box indicates the position of the zoomed-in image (B). Inset: azimuths with respect to the rutile $\mathrm{TiO}_{2}(110)$ surface. (B) Zoom $\left(90 \times 90 \AA^{2}\right)$; identified are $\mathrm{O}_{\mathrm{br}} \mathrm{H}$ (green rectangle), unit cell yellow rectangle. $(\mathbf{C})$ Zoom $(90 \times$ $90 \AA^{2}$ ) in a different imaging mode, identified are position matched $\mathrm{O}_{\mathrm{br}} \mathrm{H}$ (green rectangle) and the unit cell. A red cross identifies a large contaminant marker in both images.
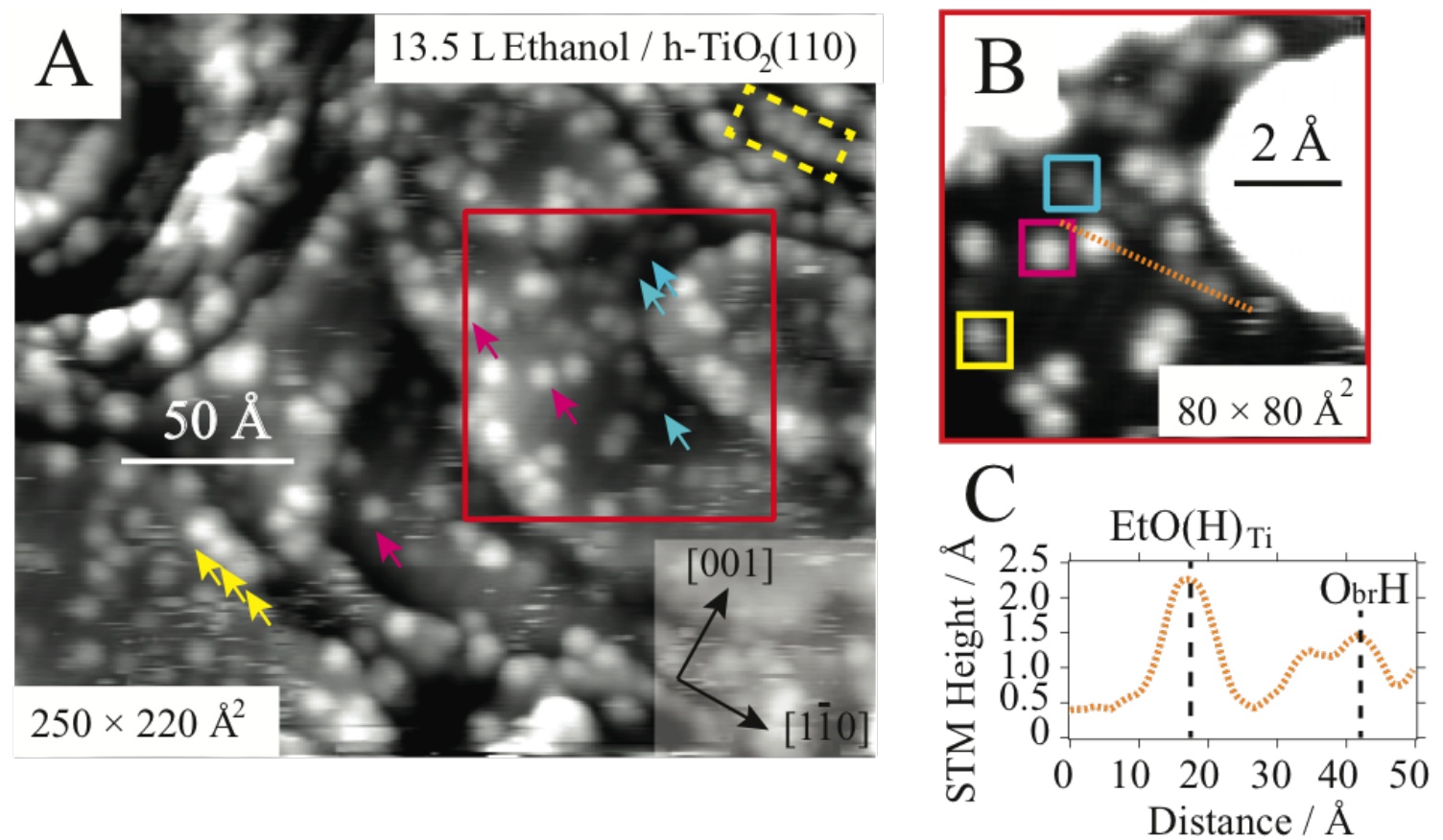

Figure 3: $300 \mathrm{~K}$ STM images of rutile $\mathrm{TiO}_{2}(110)$. (A) $250 \times 220 \AA^{2}(+1.38 \mathrm{~V}$ sample bias, $0.09 \mathrm{nA})$ surface exposed to $13.5 \mathrm{~L}$ of ethanol at RT. The pink arrows identify EtOH/EtO-, blue arrows identify $\mathrm{O}_{\mathrm{br}} \mathrm{H}$ species. The yellow arrows and dashed rectangle highlights adsorbate features at upper step edges. The red box identifies the zoom location in (B). Inset: the principal azimuths with respect to the $(110)$ surface. $\left(\right.$ B) $\mathrm{A}$ zoom $\left(80 \times 80 \AA^{2}\right)$ of the ethanol/TiO $2(110)-(1 \times 1)$ surface, $\mathrm{Ti}_{5 c}-\mathrm{EtO}(\mathrm{H})$ species (pink box), $\mathrm{Ti}_{5 \mathrm{c}}-\mathrm{EtO}_{\mathrm{s}}$ (yellow box) and $\mathrm{O}_{\mathrm{br}} \mathrm{H}$ (blue box) are identified. The dashed orange line indicates a line profile position in $(\mathbf{C})$. (C) STM height profile from image above.

Numerous STM studies have confirmed the adsorption of EtOH at $\mathrm{Ti}_{5 \mathrm{c}}$ sites.[20,22,26] The experimental work is supported by computational studies[29,32] which suggest that the two most energetically feasible adsorption configurations involve coordination of the EtO-H atop the $\mathrm{Ti}_{5 \mathrm{c}}$ with and without scission of the O-H bond (pink arrows and boxes in images Figure 3A, B). Further core level spectroscopy studies of these species are given in section 4. In between these rows are bright features of $\sim 0.8 \AA$ height (indicated by the blue arrows and box in Figure 3A, 2B), attributed here to $\mathrm{O}_{\mathrm{br}} \mathrm{H}$ species. A line profile (orange dashed line Figure 3C) depicts an $\mathrm{Obr} H$ and an ethanol or ethoxy species on the terrace.

\section{Ethanol/Rutile $\mathrm{TiO}_{2}(110)$ UV photoreactions: Mass Spectrometry}

The masses $\mathrm{m} / \mathrm{e} \mathrm{15,} \mathrm{29,} \mathrm{31,} 44$ were monitored during the photoreaction $\left(10 \mathrm{mWcm}^{-2} \sim 1.84\right.$ $\times 10^{16}$ photon s $\mathrm{s}^{-1} \mathrm{~cm}^{-2}$ ) of $\mathrm{TiO}_{2}(110)$ following exposure to $13.5 \mathrm{~L}$ ethanol at $300 \mathrm{~K}$ in a background of 
$\mathrm{O}_{2}$ in the range of $8 \times 10^{-9}-3 \times 10^{-7}$ mbar. Shown in Figure 4A are mass spectra traces of $\mathrm{m} / \mathrm{e}$ 15, representing the methyl radical resulting from $\mathrm{C}-\mathrm{C}$ bond scission. In Figure $4 \mathrm{~B}$ are the corresponding mass spectra for $\mathrm{m} / \mathrm{e} 29$, which represents the $\mathrm{CHO}$ fragment of $\mathrm{CH}_{3} \mathrm{CHO}$ after subtraction of the corresponding fragmentation patterns of ethanol. A sharp increase after opening the UV shutter and subsequent signal attenuation from the depletion of surface bound reactant is observed. A small rising signal of $\mathrm{m} / \mathrm{e} 31$ (not shown due to its minor contribution) upon opening of the shutter may have resulted from molecular as well as re-combinative desorption of surface bound species $\mathrm{CH}_{3} \mathrm{CH}_{2} \mathrm{O}-(\mathrm{a})$ and $\mathrm{OH}_{\mathrm{br}}(\mathrm{a})$. Each trace represents a separate experiment performed on a freshly prepared, rutile $\mathrm{TiO}_{2}(110)$ sample after dosing ethanol $(13.5 \mathrm{~L})$ in the dark.

The $\mathrm{CH}_{3} \cdot$ spectra (Figure 4A) display a sharp peak with a fast decay to the baseline value increasing monotonically with background $\mathrm{O}_{2}$ pressure (red to dark blue). Zehr and Henderson[34] studied the photo-fragmentation of an acetaldehyde-oxygen complex at $200 \mathrm{~K}$ on rutile $\mathrm{TiO}_{2}(110)$. Our results investigating ethanol photochemistry at room temperature display a qualitative similarity; i) A clear dependence on the partial pressure of $\mathrm{O}_{2}$ is seen; ii) a similar peak shapes to those observed by Zehr and Henderson, who resolved them into fast and slow coverage-dependent decays channels. Kershis et al. also observed the methyl radical by photoreaction of ethanol on rutile $\mathrm{TiO}_{2}(110)$ but only at low temperature $(105 \mathrm{~K})$.[33]

The m/e 29 (CHO) signal (Figure 4B) is attributed to desorption of molecular acetaldehyde. Acetaldehyde is the dehydrogenation product of ethanol after the abstraction of the alpha carbonhydrogen atom (alpha refers to the carbon of the functional group, $-\mathrm{CH}_{2} \mathrm{OH}$, while hydrogen atoms of the methyl group, $-\mathrm{CH}_{3}$, are commonly referred to as beta-hydrogen atoms) following hole trapping on $\mathrm{TiO}_{2}$ surfaces.[22] [29] The spectra display a peak jump with a slow decay over the 180 s period. The peaks heights display an inverse (albeit weak) dependence on $\mathrm{O}_{2}$ pressure. The decrease of acetaldehyde desorption and the increase of the $\mathrm{CH}_{3}$ - radical may result from a greater rate of formation of an oxygen-acetaldehyde complex, as proposed by Zehr and Henderson,[34] and subsequent photo-fragmentation at higher $\mathrm{O}_{2}$ pressures, to a methyl radical and a surface formate as will be discussed below. It could also be a parallel reaction, where an ethanol molecule reacts directly with $\mathrm{O}_{2}$ and holes to make water, formate and $\mathrm{CH}_{3}$ - radical. Both possibilities will be addressed below.

The integrated peak areas of m/e 15 and $\mathrm{m} / \mathrm{e} 29$ were calculated by placing a baseline connecting the intial and final flat regions after UV irradiation, and numerically integrating by the trapezium rule in the 'UV-on' region (an illustrative example is shown in Figure 4B). These areas are plotted in Figure 4C (with different axes) with respect to the $\mathrm{O}_{2}$ background pressure. This computed area-dependence on $\mathrm{O}_{2}$ pressure displays a logarithmic increase of the $\mathrm{CH}_{3}$ - radicals $(\mathrm{m} / \mathrm{e} 15)$ formation and a logarithmic decrease of the acetaldehyde (m/e 29) formation with increasing gas phase $\mathrm{O}_{2}$ pressure. This dependence is demonstrated by the straight linear regression fits in Figure 4D $\log$-log plots of these computed areas with respect to $\mathrm{P}_{\mathrm{O} 2}$. The numerical values of the gradients for 
methyl radical and acetaldehdye are 0.56 and - 0.1. From the decay of signal in Figure 4A the time constants can be extracted. To compute this we have fitted the signal with two exponentials. The inverse of the time constat $(\tau)$ is the rate constant $(\mathrm{k})$ from which we have extracted the cross section, $\mathrm{Q}$, of the reaction $(\mathrm{k}=\mathrm{QF})$ knowing the light flux, $\mathrm{F}\left(1.84 \times 10^{16}\right.$ photons $\left.\mathrm{cm}^{-2} \mathrm{~s}^{-1}\right)$. The computed kinetic parameters are presented in table 1 for the $\mathrm{CH}_{3}$ radical signals at the different oxygen pressures. Also shown in the table is $t_{1,2}$ which represents the time at which both exponentials become equal (when both regimes cross).

Table 1. Effect of oxygen pressure on the decay signal of $\mathrm{CH}_{3}$ radicals produced upon the $\mathrm{C}-\mathrm{C}$ bond dissociation of ethoxides on the surface of $\mathrm{TiO}_{2}(110)$ rutile in the presence of $\mathrm{UV}$ light with a flux, $\mathrm{F}$, of $1.84 \times 10^{16}$ photons $\mathrm{cm}^{2} \mathrm{~s}^{-1}$. Fitting of the signal was conducted using the function $\mathrm{y}=\mathrm{A}+\mathrm{B} \exp (-$ $\left.\left(\mathrm{t}-\mathrm{t}_{0}\right) / \tau_{1}\right)+\mathrm{C} \exp \left(-\left(\mathrm{t}-\mathrm{t}_{0}\right) / \tau_{2}\right)$. A is the offset constant and $\mathrm{B}$ and $\mathrm{C}$ are pre-factors. $t_{1,2}$ was obtained from $\operatorname{Bexp}\left(-\left(\mathrm{t}-\mathrm{t}_{0}\right) / \tau_{1}\right)=\operatorname{Cexp}\left(-\left(\mathrm{t}-\mathrm{t}_{0}\right) / \tau_{2}\right) . \mathrm{Q}_{1}$ and $\mathrm{Q}_{2}$ are obtained from $k=Q F$.

\begin{tabular}{|r|r|r|r|r|r|r|r|}
\hline $\mathrm{P}_{02}(\mathrm{mbar})$ & \multicolumn{1}{|c|}{$\tau_{1}(\mathrm{~s})$} & $\tau_{2}(\mathrm{~s})$ & $\mathrm{k}_{1}\left(\mathrm{~s}^{-1}\right)$ & $\mathrm{k}_{2}\left(\mathrm{~s}^{-1}\right)$ & $\mathrm{Q}_{1}\left(\mathrm{~cm}^{2}\right)$ & $\mathrm{Q}_{2}\left(\mathrm{~cm}^{2}\right)$ & $t_{1,2}(\mathrm{~s})$ \\
\hline $3 \times 10^{-7}$ & 2.6 & 35 & 0.385 & 0.0286 & $2 \times 10^{-17}$ & $1.6 \times 10^{-18}$ & 4.1 \\
\hline $1 \times 10^{-7}$ & 2.6 & 48 & 0.385 & 0.0208 & $2 \times 10^{-17}$ & $1.1 \times 10^{-18}$ & 5.4 \\
\hline $6 \times 10^{-8}$ & 4 & 52 & 0.250 & 0.0192 & $1.3 \times 10^{-17}$ & $1 \times 10^{-18}$ & 10.1 \\
\hline $2 \times 10^{-8}$ & 5 & 60 & 0.200 & 0.0167 & $1.1 \times 10^{-17}$ & $0.9 \times 10^{-18}$ & 12.7 \\
\hline $8 \times 10^{-9}$ & 5.1 & 75 & 0.196 & 0.0133 & $1.0 \times 10^{-17}$ & $0.7 \times 10^{-18}$ & 11.7 \\
\hline
\end{tabular}



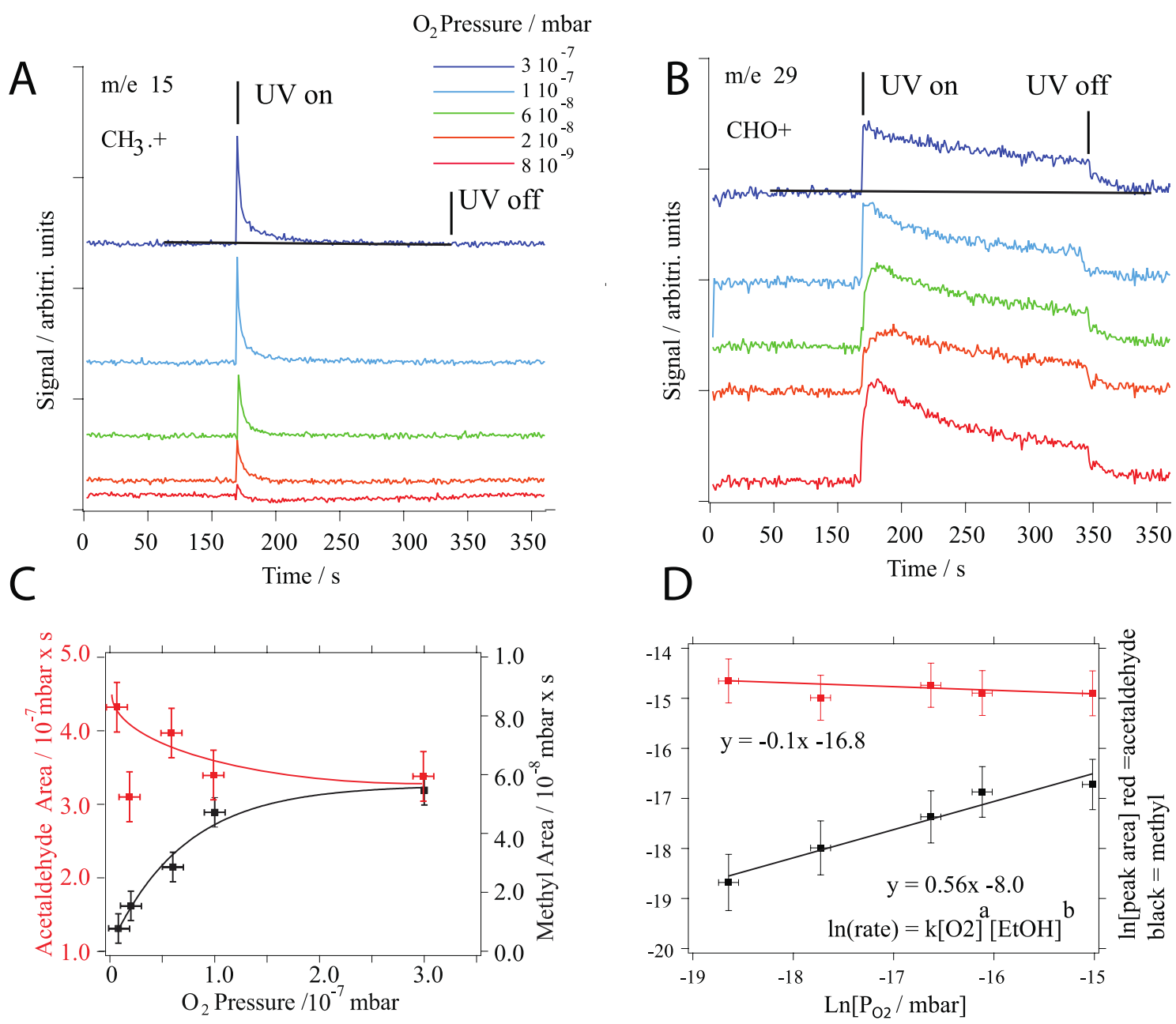

Figure 4: $300 \mathrm{~K}$ on-line mass spectrometry of the masses m/e 29 and m/e 15 during exposure of $0.06 \mathrm{ML}$ ethanol, ethoxy/rutile $\mathrm{TiO}_{2}(110)$ to UV light in the presence of $\mathrm{O}_{2}\left(8 \times 10^{-9}-3\right.$ $\times 10^{-7} \mathrm{mbar}$ ). (A) Mass spectra traces for $15 \mathrm{~m} / \mathrm{e}$ after deductions. B) Mass spectra traces for $29 \mathrm{~m} / \mathrm{e}$ after deductions. (C) Plot of the integrated spectra using a horizontal baseline defined in (A) and (B) of the m/e 15 and 29 masses. D) Plot of the $\ln \left[\right.$ area] vs $\ln \left[\mathrm{PO}_{2}\right]$ for $\mathrm{m} / \mathrm{e} 15$ and 29 masses.

\section{Ethanol/Rutile $\mathrm{TiO}_{2}(110)$ UV photoreactions: STM}

Shown in Figure 5 are $300 \mathrm{~K}\left(2 \times 10^{-10}\right.$ mbar $)$ STM images recorded at a $+2 \mathrm{~V}$ sample bias and $0.08 \mathrm{nA}$ tunneling current of $0.06 \mathrm{ML}$ ethanol, ethoxy/rutile $\mathrm{TiO}_{2}(110)$ surface directly after exposure to $\mathrm{UV}$ light in the presence of molecular $\mathrm{O}_{2}\left(\mathrm{P}_{\mathrm{O} 2}\right.$ is in the range $\left[8 \times 10^{-9}, 3 \times 10^{-7}\right]$ mbar). These images display a surface decorated by bright protrusions of ca. 5-6 $\AA$ diameter and height ca. 1-2 $\AA$, as seen in Figure 3B. Moreover, frequent streaks in height as was present on the ethanol, ethoxy/rutile $\mathrm{TiO}_{2}(110)$ surface in the "dark" were observed for the lowest $\mathrm{P}_{\mathrm{O} 2} 8 \times 10^{-9}$ mbar; this reduced with increasing $\mathrm{O}_{2}$ pressure, attributed to a reduction in loosely bound species.[50] A $230 \times 200 \AA^{2}$ image recorded at the lowest $\mathrm{O}_{2}$ pressure (Figure 5A) contains bright rows; three are identified by blue 
parallel lines and assigned to $\mathrm{Ti}_{5 \mathrm{c}}$ rows. Large area images at higher pressure are also presented (Figure 5C, E). Green (and pink) dashed lines of $6.5 \AA$ separation are overlaid on-top of the $\mathrm{Ti}_{5 \mathrm{c}}$ rows on the lower (and upper) terraces in the high magnification images (Figure 5B, D, F); it is apparent that the majority of the adsorbates lie on these rows and are therefore coordinated to $\mathrm{Ti}_{5 \mathrm{c}}$. Three different observed adsorbates are labeled: 'A1' (blue box), 'A2' (red box), 'A3' (purple box), differentiated by their apparent height in STM and their position relative to the $\mathrm{Ti}_{5 \mathrm{c}}$ rows. The arrows of the corresponding color identify these features in Figure 5A, C, E.
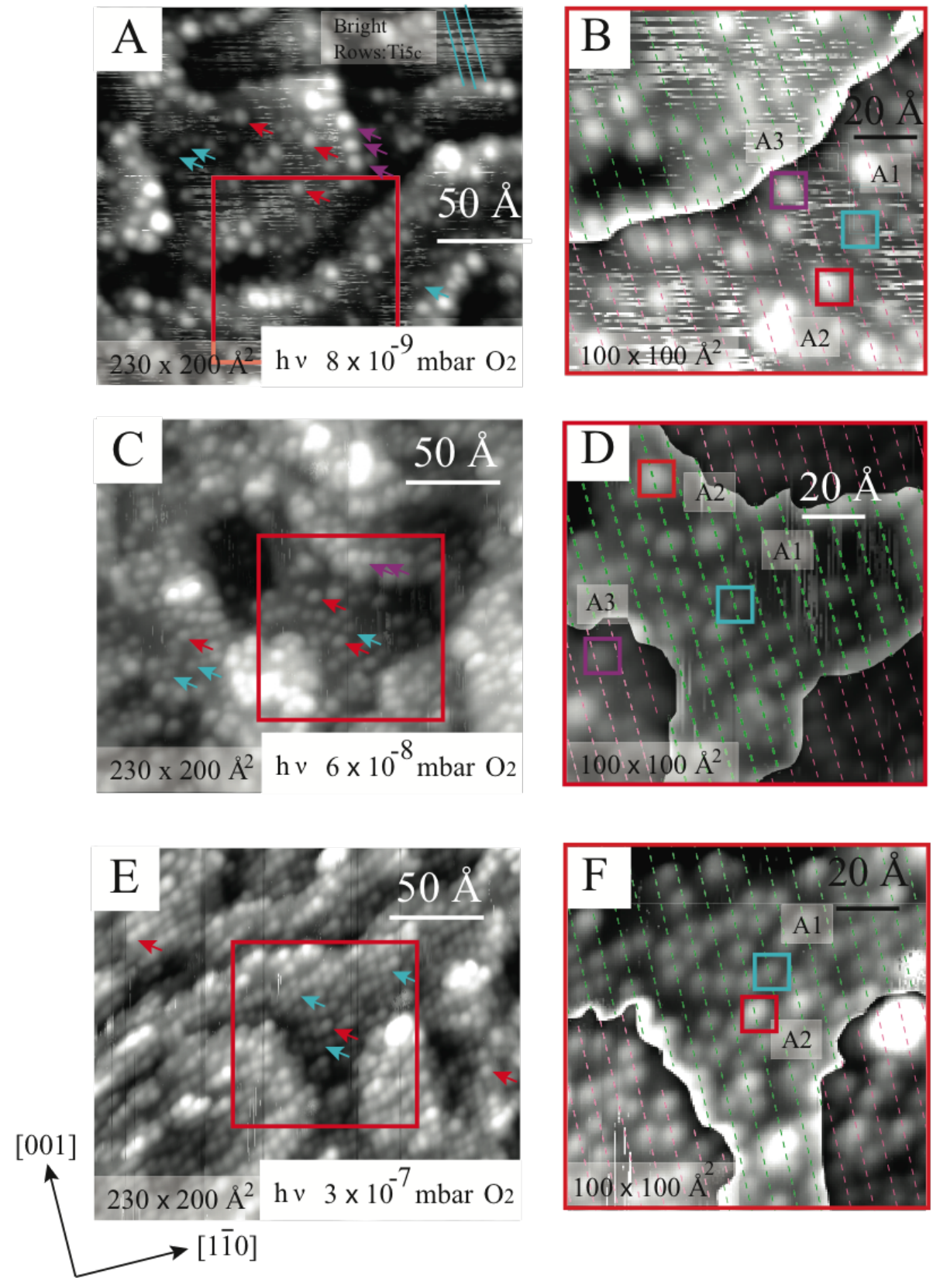

Figure 5: $300 \mathrm{~K}$ STM images $(+2 \mathrm{~V}, 0.08 \mathrm{nA})$ of a $13.5 \mathrm{~L}$ ethanol exposed rutile $\mathrm{TiO}_{2}(110)-(1 \times 1)$ surface after 180 seconds UV light at the indicated $\mathrm{P}_{\mathrm{O} 2}$. Green (upper terrace) and pink (lower terrace) dashed lines are overlaid coincident with the $\mathrm{Ti}_{5 \mathrm{c}}$ rows in some images. The (110) surface azimuths 
directions are indicated at the bottom of the figure.

(A) $230 \times 200 \AA^{2}$ STM image $\left(8 \times 10^{-9}\right.$ mbar) and (B) $100 \times 100 \AA^{2}$ zoom, A1 (blue box), A2 (red box), A3 (purple box) features are identified.

(C) $230 \times 200 \AA^{2}$ STM image $\left(6 \times 10^{-8}\right.$ mbar) (D) $100 \times 100 \AA^{2}$ zoom, A1 (blue box), A2 (red box), A3 (purple box) features are identified.

(E) $230 \times 200 \AA^{2} \mathrm{STM}$ image $\left(8 \times 10^{-9}\right.$ mbar) (F) $100 \times 100 \AA^{2}$ zoom, A1 (blue box), A2 (red box), A3 (purple box) features are identified.

A
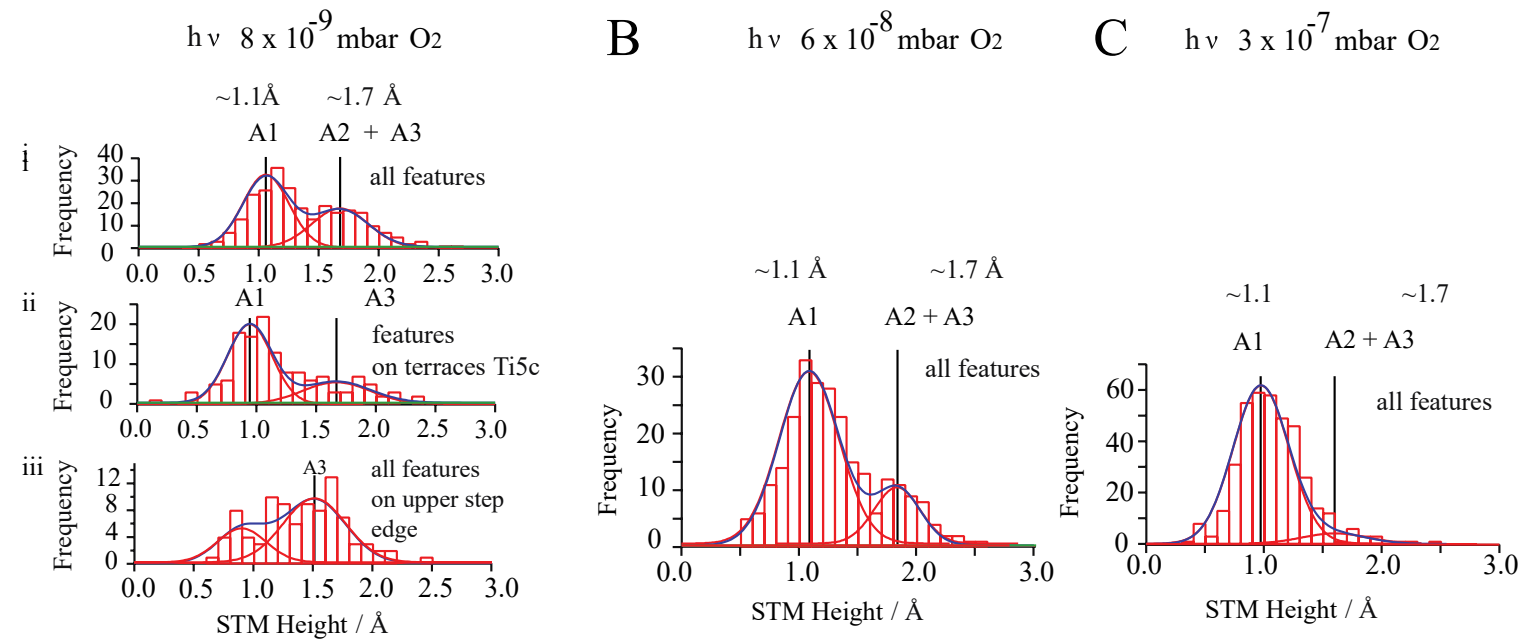

Figure 6

(A) Histogram of a 46,000 $\AA^{2}$ area after UV light in the presence of $\mathrm{P}_{\mathrm{O} 2}=8 \times 10^{-9} \mathrm{mbar}$.

i) All features, ii) features on $\mathrm{Ti}_{5 \mathrm{c}}$ terrace sites, iii) features on upper step edges.

(B) Histogram of the heights measured from a $260 \times 260 \AA^{2}$ image, fitted with two Gaussian functions after $\mathrm{UV}$ light in the presence of $\mathrm{P}_{\mathrm{O} 2}=6 \times 10^{-8}$ mbar.

(C) A histogram of the heights measured from a $300 \times 300 \AA^{2}$ image after UV light in the presence of $\mathrm{P}_{\mathrm{O} 2}=3 \times 10^{-7} \mathrm{mbar}$, fitted with two Gaussian functions.

In all the adsorbate height is determined from a topographic line profile, computing the difference in height of the adsorbate and minimum height of the bridging oxygen row in the empty sample state imaging mode.

The assignment of these surface features is aided by histograms of measured STM heights. A histogram was compiled from an area of $46,000 \AA^{2}$ of the $8 \times 10^{-9} \mathrm{mbar}^{\mathrm{O}_{2}}$ image (Figure 5A) and presented in Figure 6A(i); this is fitted by two Gaussian functions (FWHM, $2.8 \AA$ ): centered at $1.1 \AA$ $(\sim 0.05 \mathrm{ML})$ and $1.7 \AA(\sim 0.03 \mathrm{ML})$. A histogram of the two features on the $\mathrm{Ti}_{5 \mathrm{c}}$ rows is displayed in Figure 6A(ii). Here the $1.1 \AA$ adsorbate species are denoted as 'A1' $(0.05 \mathrm{ML} \pm 0.01 \mathrm{ML})$; a new photoreaction product not present on the "dark" ethanol/ $\mathrm{TiO}_{2}(110)$, such a species has been observed but not assigned previously.[22] The second is denoted 'A2' (ca. 1.7, $0.015 \mathrm{ML} \pm 0.01 \mathrm{ML}$ ), which is consistent with ethanol/ethoxide species observed on the ethanol/rutile $\mathrm{TiO}_{2}(110)$ (Figure 3). Features directly adjacent to and on the upper step edges were measured and their histogram (Figure 6A(iii)) indicates a major peak at $\sim 1.7 \AA$ denoted 'A3' (ca. $1.7 \AA \pm 2 \AA, 0.015 \mathrm{ML} \pm 0.01 \mathrm{ML}$ ) and minor features at $\sim 1.1 \AA$.

STM images $\left(230 \times 200 \AA^{2}\right.$ and zoom $\left.100 \times 100 \AA^{2}\right)$ recorded after UV light exposure at the 
intermediate $\mathrm{O}_{2}$ pressure of $6 \times 10^{-8} \mathrm{mbar}$ (Figure 5C, D) and highest of $3 \times 10^{-7} \mathrm{mbar}_{2}$ pressure (Figure 5E, F) show that the $1.1 \AA$ ' A1' adsorbates show an increase in surface density; $0.076 \mathrm{ML}$ at $6 \times 10^{-8} \mathrm{mbar}$ and $0.14 \mathrm{ML}$ at $3 \times 10^{-7} \mathrm{mbar}$. The increase in the overall adsorbate density at $3 \times 10^{-7}$ mbar is due to unavoidable traces of ethanol in the dosing line (the sticking coefficient of ethanol is many orders of magnitudes higher than that of molecular oxygen on $\mathrm{TiO}_{2}$ ). Analyzing positions of the adsorbates; these are arranged with a distance between of $\sim 6 \AA$ forming $(1 \times 2)$ chains along the rutile [001] surface direction. Histograms were compiled from adsorbates STM heights (areas of 46,000 $\AA^{2}$ ) for both $6 \times 10^{-8}$ mbar and $3 \times 10^{-7} \mathrm{mbar}_{\mathrm{PO}_{2}}$ and are presented in Figure 5B, C. There is a clear increase in the 'A1': ('A2' 'A3') ratio with increasing $\mathrm{P}_{\mathrm{O} 2}$. This suggests that the $\mathrm{A} 2$, and $\mathrm{A} 3$ species are reactants or intermediates which photo-react in the presence of increasing $\mathrm{O}_{2}$ pressures. Such a phenomenon was observed by Hansen et al,[22] notably the 'A3' features located at the step edges are present in lower density; these features were previously assigned as ethanol dissociated in the step edge vacancies. The low density of adsorbates along the bridging $\mathrm{O}_{2 \mathrm{c}}$ rows in our STM image indicates that few ethanol derived photo-oxidation products remain bound with the oxygen incorporated in the $\mathrm{O}_{2 \mathrm{c}}$ site.[22] In addition the $\mathrm{O}_{\mathrm{br}} \mathrm{H}$ expected form the hydrogen abstraction of ethanol are not present on the surface in STM, it is expected that these species are abstracted by molecular $\mathrm{O}_{2 .[16]}$

There are several possible photoreaction reactant/product assignments of the terrace species 'A1' (1.1 $\AA)$ and 'A2' $(1.7 \AA)$ on the $\mathrm{Ti}_{5 \mathrm{c}}$ rows. These include ethoxy species thought to be present on the surface before UV irradiation, and formates. Acetaldehyde can be excluded because it desorbs at 300 $\mathrm{K}$ as indicated by our mass spectrometry data as well as earlier work.[34] Support for the formate assignment comes from C1s XPS spectra recorded following UV light irradiation.[23] Moreover, formate formation was inferred from acetaldehyde-TPD by Zehr and Henderson[34] with the prior observance of methyl radical during photoreaction. Further support to this assignment is given in section 4 , below.

Shown in Figure 7A are plots of the STM measured coverage of A1 species attributed to formates (red) in ML as well as those of the $\mathrm{CH}_{3}$ - radical desorbed in the gas phase (green). The production of both formates and $\mathrm{CH}_{3}$ radicals as a function of oxygen pressure has the same profile. This indicates that both originate from the same intermediate. An apparent plateau in coverage with increasing $\mathrm{O}_{2}$ pressure is observed at $\sim 0.14 \mathrm{ML}$. The change in coverage as a function of $\mathrm{O}_{2}$ pressure can be fitted by a logarithmic function. Moreover, it is clear that the mass spectrometry $\mathrm{CH}_{3} \cdot$ pressure has a similar fitting function. This further confirms that formates result from the scission of the C-C bond in ethoxy/ethanol by hole capture. The separation of these species along [001], corresponds to twice the $\mathrm{Ti}_{5 \mathrm{c}}$ separation suggesting a bidentate bonding configuration, together with their stability under photons give further evidence to their attribution to formates (carboxylates are largely unreactive to when compared to ethoxides [51]). 

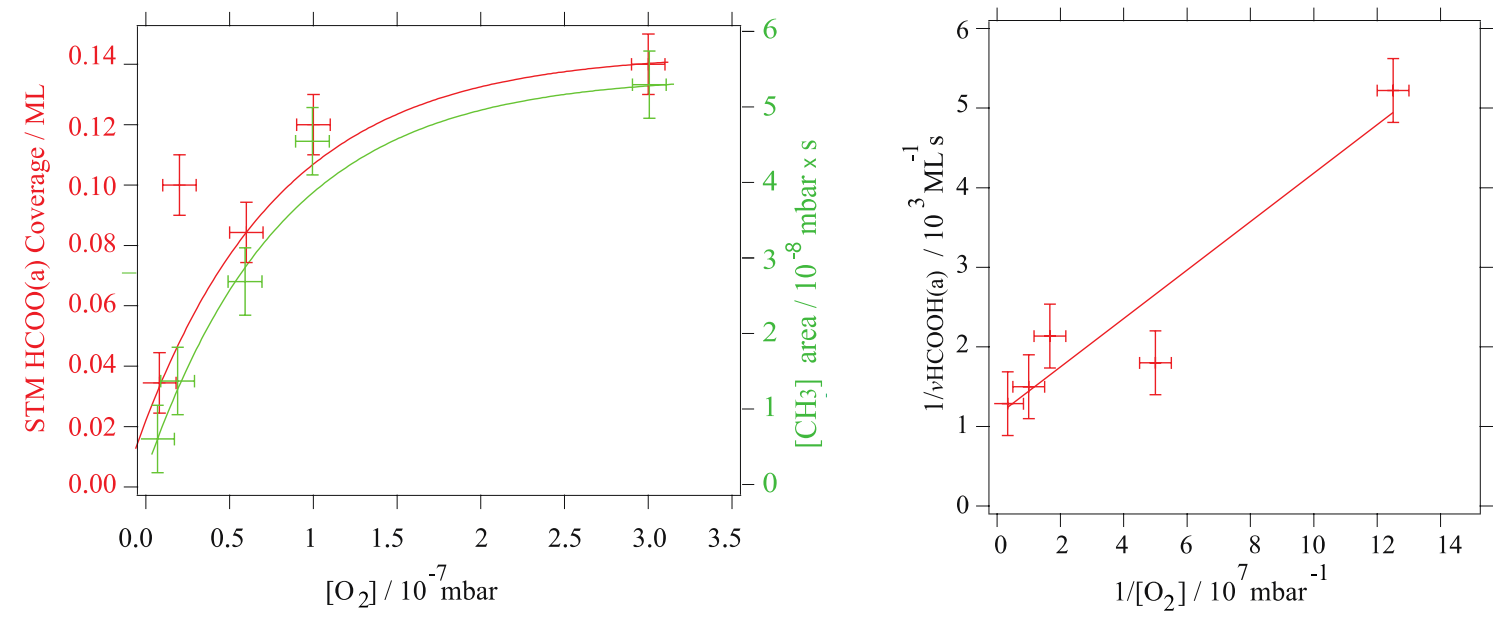

Figure 7: (A) A plot of the STM determined coverage of A1 in ML, which is assigned to formate, against $\mathrm{O}_{2}$ pressure (red). On a different $\mathrm{Y}$-axis is shown the QMS response of the $\mathrm{CH}_{3} \bullet$ radical (green) in mbar. $\mathrm{R}^{2}$ values are 0.98 and 0.67 for the mass spectrometry data (green) and surface coverage (red), respectively. The error bars are both $+/-0.1 \times 10^{-7}$ mbar for the $x$-axis and $+/-0.5 \times$ $10^{-8}$ mbar and +/- $0.01 \mathrm{ML}$ for the y-axes: green $\left[\mathrm{CH}_{3}\right.$ radicals ] and red (coverage of $\mathrm{HCOO}(\mathrm{a})$ ) traces, respectively. (B) A Langmuir-Hinshelwood plot of the mean STM coverage rate in MLs ${ }^{-1}$ determined from the 180 second exposure time. $\mathrm{R}^{2}$ value for linear fit $=0.89$.

The species A2 of ca. $1.7 \AA$ height is consistent with ethoxy dissociated by the action of the UV light exposure[28] or during adsorption,[22] on the basis of comparison to the STM images recorded in the dark of the ethanol/rutile $\mathrm{TiO}_{2}(110)$ surface. However, a reaction intermediate could also be formed; notably Hansen et al. observed two new species, both occupying two $\mathrm{Ti}_{5 \mathrm{c}}$ sites after photo-oxidation of ethanol in the presence of $\mathrm{O}_{2}$ on the surface of rutile $\mathrm{TiO}_{2}(110)$.[22] The adsorbate A3, which has a reduced reactivity at the step edge are most probably dissociated EtOs, identified on the ethanol/rutile $\mathrm{TiO}_{2}(110)$ surface prior to UV light exposure;[22,26] these were demonstrated previously to be less photo-reactive than $\mathrm{Ti}_{5 \mathrm{c}}$ adsorbed ethanol.[22]

\section{Ethanol/Rutile $\mathrm{TiO}_{2}$ (110) UV photoreactions: XPS (C1s)}

To give further evidences for the assignments of the different species observed during the STM study we have conducted core level spectroscopy at similar conditions. Figure 8 presents XPS C1s upon adsorption of ethanol at $240 \mathrm{~K}$ at saturation coverage followed by heating at the indicated temperatures up to $300 \mathrm{~K}$. The objective here is to confirm that at $300 \mathrm{~K}$ most of surface adsorbates are ethoxides. Also, from the attenuation of the Ti2p and O1s following the method that we have previously used $[23,52,53]$ surface coverage is found to be equal to $0.5-0.6$ based on Ti2p and O1s lines (see the table in figure S1). Also shown in figure S2 the difference XPS C1s spectra between the 240K-dosed surface and those heated at the indicated temperatures. One peak centered at about $286.7 \mathrm{eV}$ that is deconvoluted to two at about $287.1 \mathrm{eV}$ and $285.4 \mathrm{eV}$ attributed to the contribution of $-\mathrm{CH}_{2} \mathrm{OH} /-$ $\mathrm{CH}_{2} \mathrm{O}$ - and $-\mathrm{CH}_{3}$ groups of ethanol/ethoxides $[23,30]$. The difference spectra show the removal of 
molecular ethanol in line with what has been previously observed on the $\{011\}$-facetted rutile $\mathrm{TiO}_{2}(001)$ single crystal [14]; there is about $0.5 \mathrm{eV}$ shift in the binding energy between molecular ethanol and its dissociated form. The decrease of the $-\mathrm{CH}_{2} \mathrm{O}$ - signal, with increasing temperature, when compared to that of $-\mathrm{CH}_{3}$ signal is in part attributed to screening effect due to the mode of adsorption (via the $\mathrm{O}$ atoms of ethoxides) on Ti cations. Figures S3-S5 present XPS C1s, Ti2p and O1s before dosing ethanol, after surface saturation with ethanol at $300 \mathrm{~K}$ and after excitation with UV light for 30 minutes with light flux equal $7.4 \mathrm{~mW} / \mathrm{cm}^{2}$ in the $320-400 \mathrm{~nm}$ range and at an $\mathrm{O}_{2}$ partial pressure of $5 \times 10^{-7} \mathrm{mbar}$. Before adsorption there is a small adventitious carbon peak at a BE of about $284.8 \mathrm{eV}$. Figure 9 presents the same $\mathrm{C} 1 \mathrm{~s}$ spectra before and after UV reaction. Before reaction, the signature of ethoxides is clear with the two peaks at ca. 285.5 and $286.8 \mathrm{eV}$. In the fitting, the peak at $284.8 \mathrm{eV}$ (adventitious carbon) is kept constant. Upon UV excitation, two main changes occurred. A considerable attenuation of the overall signal by about half (see tables in figures S4 and S5) and the appearance of a peak at ca. $289.7 \mathrm{eV}$. Both are due to reaction with UV light in the presence of oxygen. The decrease is due to the removal of ethoxides as acetaldehyde and $\mathrm{CH}_{3}$ radicals (as seen by mass spectroscopy, figure 4) and the $289.7 \mathrm{eV}$ peak (carboxylate) is assigned to formate species. The assignment to formates and not to acetates is based on the desorption of a methyl radical during the reaction. The photocatalytic activity of carboxylates with $\mathrm{O}_{2}$ over UV is much slower than that of alcohols [54] that is the reason it ends by converging the surface as seen by STM, see species A1 in figures 5 and 6. In order to further confirm the assignment of the A1 species to formates we have conducted STM images of the $\mathrm{TiO}_{2}(110)$ single crystal surface upon exposure to formic acid at $300 \mathrm{~K}$. Figure 10 shows the characteristic $(2 \times 1)$ reconstructed surface with $6 \AA$ separation along the [001] direction in line with many other studies [41-42, 55-56].
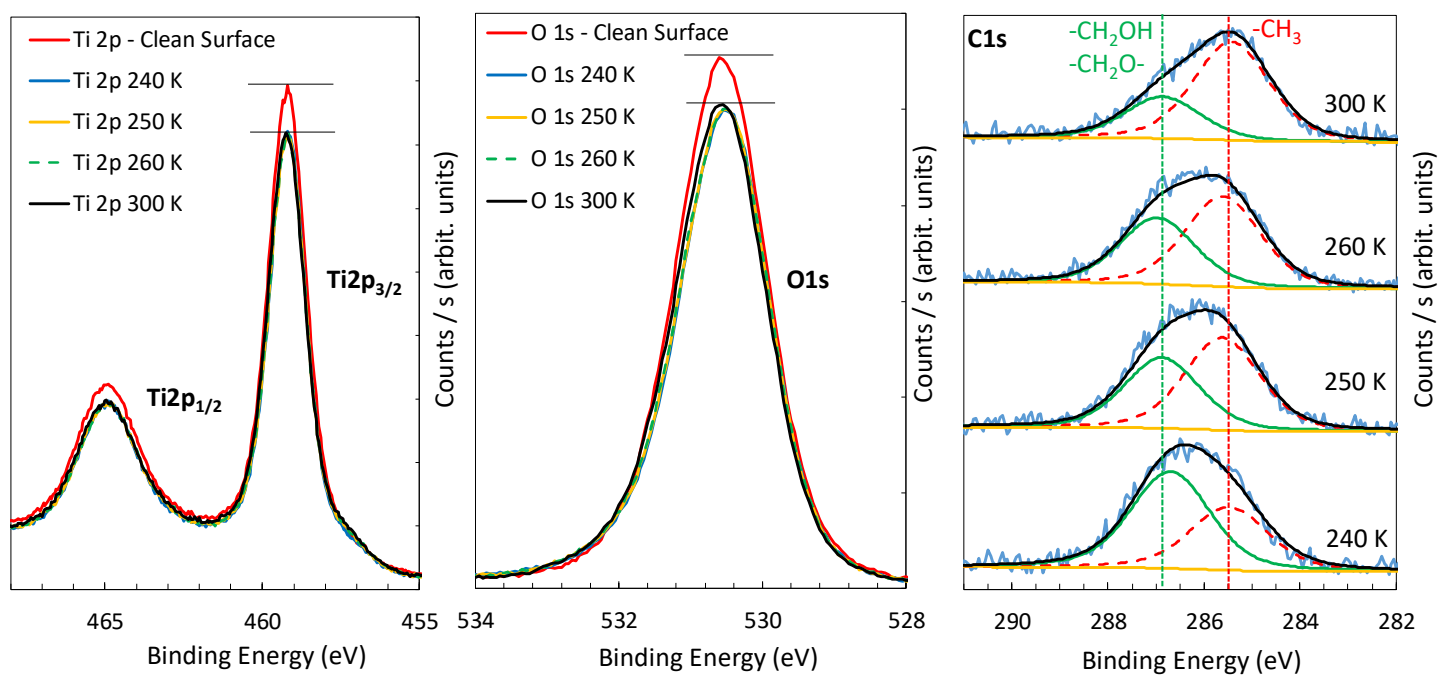

Figure 8 
XPS Ti2p, $\mathrm{O} 1$ and $\mathrm{C} 1 \mathrm{~s}$ before ethanol adsorption (clean surface) and after adsorption at $240 \mathrm{~K}$ followed by heating at the indicated temperatures up to $300 \mathrm{~K}$. The difference spectra of the $\mathrm{C} 1$ s to indicate molecular ethanol desorption are given in figure S2. Surface coverages based on the attenuation of XPS Ti2p and O1s are given in figure S1.
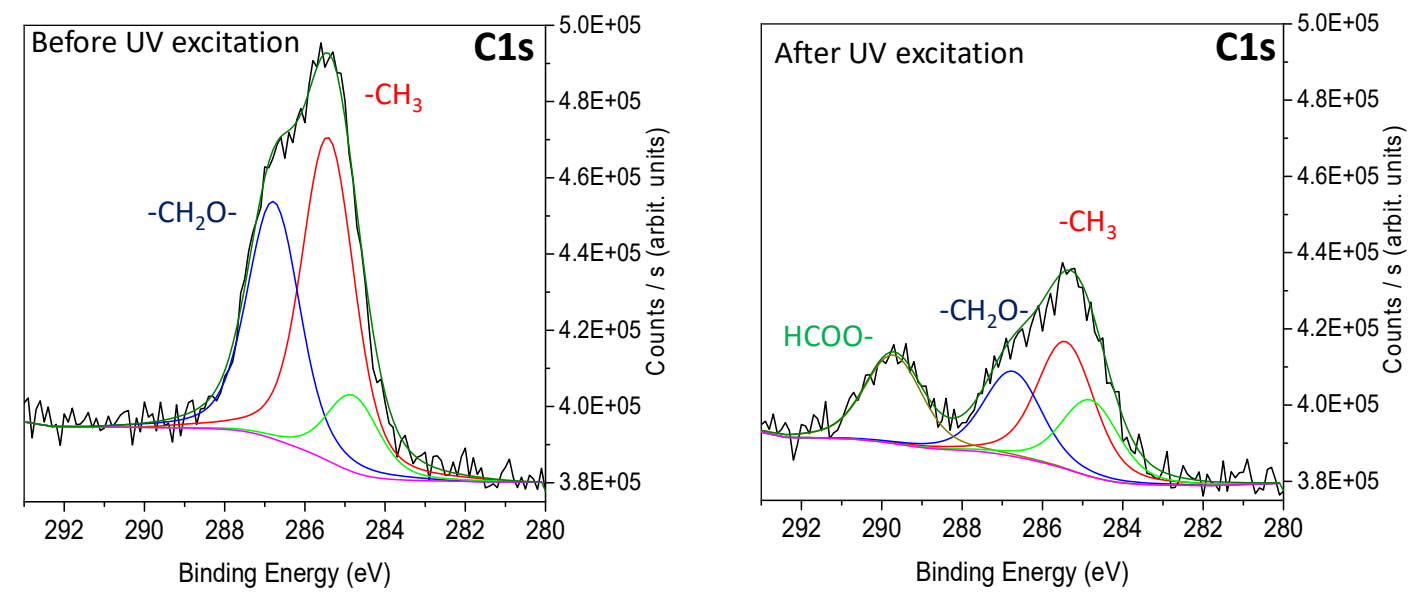

\section{Figure 9}

XPS C1s after ethanol adsorption at $300 \mathrm{~K}$ before UV excitation and after UV excitation (30 minutes in presence of $5 \times 10^{-7}$ torr of $\mathrm{O}_{2}$ ). After UV excitation, a decrease of surface coverage by about half is noticed. Surface population after UV excitation is composed of a large fraction of formate species; see figures S3-S5 for more details. 

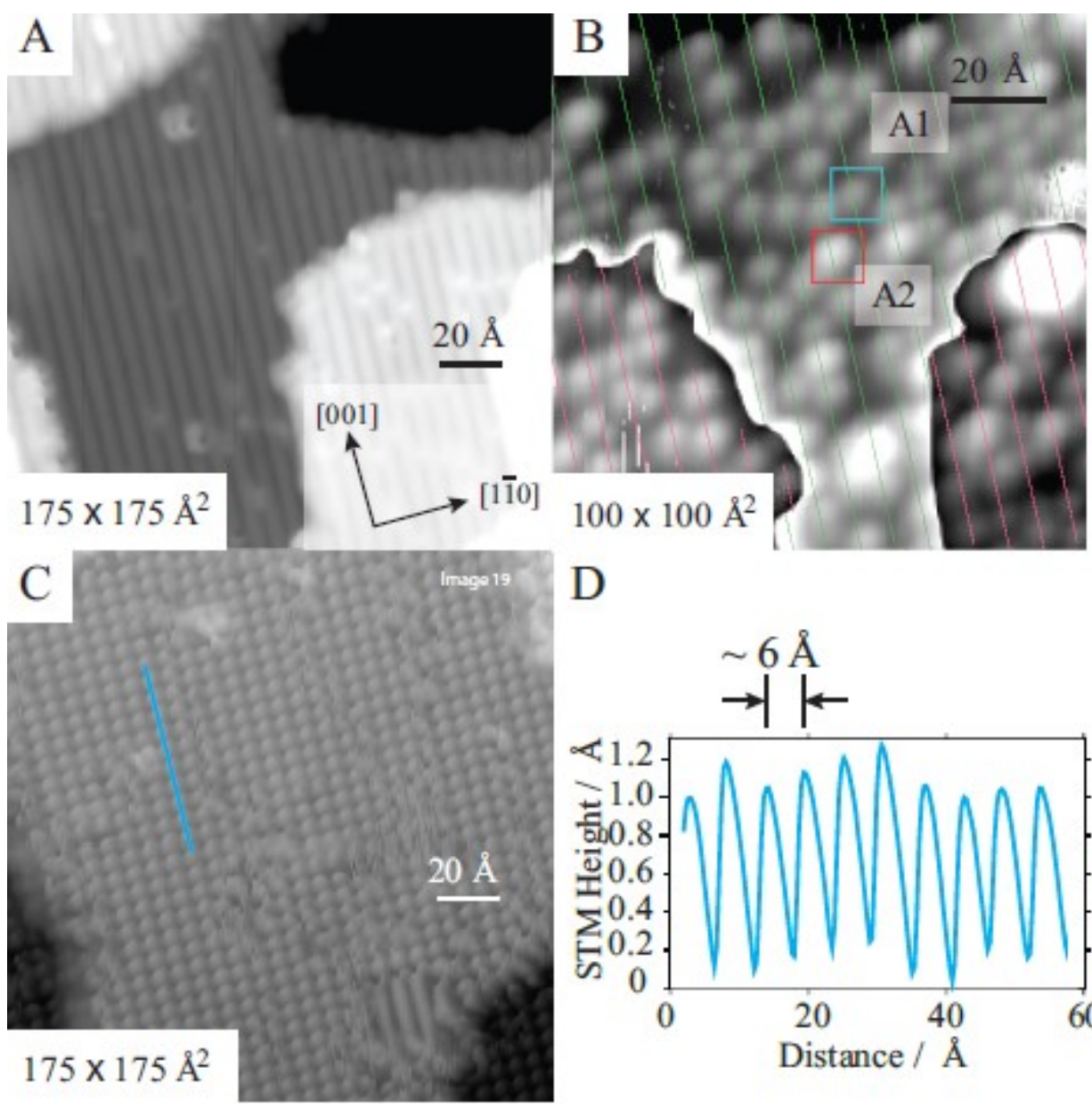

$\mathrm{D}$

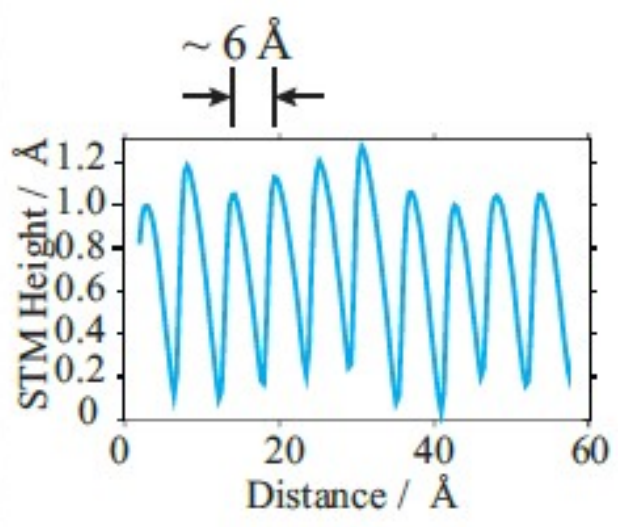

\section{Figure 10}

STM images of clean rutile $\mathrm{TiO}_{2}(110)$ surface (A). An ethanol-dosed $\mathrm{TiO}_{2}(110)$ surface after UV excitation for 30 minutes at $3 \times 10^{-7} \mathrm{mbar}(\mathrm{B})$. In $\mathrm{B}$, most species are those of formates ( 88 formates and 11 ethoxides). A formic acid-dosed $\mathrm{TiO}_{2}(110)$ surface at $300 \mathrm{~K}(\mathrm{C})$. A line profile (height versus distance) of the blue line of figure (C) indicating that the separation of $6 \AA$ along the [001] direction, characteristic of formates $(2 \times 1)$ reconstruction on the rutile $\mathrm{TiO}_{2}(110)$ surface.

The STM coverage of formate as a function of $\mathrm{O}_{2}$ pressure can be converted into a rate by dividing by the time interval of UV light exposure (180 s). This results in the mean rate $v_{H C o o(a)}$ over the duration of UV light exposure in $\mathrm{MLs}^{-1}$ where $1 \mathrm{ML}$ is $5.2 \times 10^{14}$ formate molecules. The Langmuir-Hinshelwood equation for the oxidation of ethanol to formate is

$$
v_{H C o O}(a)=k \theta_{\text {EtOH }}\left(\begin{array}{c}
K\left[O_{2}\right] \\
1+K\left[O_{2}\right]
\end{array}\right) \text { or } \begin{gathered}
1 \\
v_{H \operatorname{Coo}(a)}
\end{gathered}=\begin{array}{ccc}
1 & 1 \\
k^{\prime} & k^{\prime} K\left[O_{2}\right]
\end{array}
$$

where $k / \mathrm{s}^{-1}$ is the reaction rate constant, $\theta_{\text {StoH }} / \mathrm{ML}$ the ethanol coverage, $\mathrm{K} / \mathrm{mbar}^{-1}$ the binding 
constant of $\mathrm{O}_{2}$ on $\mathrm{TiO}_{2},\left[\mathrm{O}_{2}\right] /$ mbar the oxygen partial pressure and $k^{\prime}$ is $k \theta_{\text {EtOH. }}$. A plot of $1 /\left[0_{2}\right]$ against $1 / v_{H C u v(a)}$ is shown Figure 7B. The intercept of $1139 \mathrm{ML}^{-1} \mathrm{~s}$ is equal to $1 / k^{\prime}$ where $k^{\prime}$ is a pseudo rate constant incorporating the ethanol coverage. Assuming an initial ethanol coverage of $\sim 0.1$ ML (during the STM experiment) an average rate constant of $0.00877 \mathrm{~s}^{-1}$ in the $\mathrm{O}_{2}$ pressure range $\left[0.8 \times 10^{-8}, 3 \times 10^{-7}\right]$ is obtained. This can be converted to a rutile $\mathrm{TiO}_{2}(110)$ specific photoreaction cross-section $\mathrm{Q}$ where $F Q=k$. The photon flux of above band gap $(3 \mathrm{eV})$ light was $1.8 \times 10^{16}$ photons $\mathrm{s}^{-1} \mathrm{~cm}^{-2}$. Therefore, a mean of $4.9 \times 10^{-19} \mathrm{~cm}^{2}$ is determined over the $180 \mathrm{~s}$. This is close to the value reported previously from TPD data by Zehr and Henderson of $2 \times 10^{-19} \mathrm{~cm}^{2}$.[34]

Scheme 1 presents the reaction network summary. Upon exposure of the surface of $\mathrm{TiO}_{2}(110)$ single crystal to ethanol at RT it is covered by ethoxides. When the surface is exposed to UV light electronhole pairs are formed in the $\mathrm{TiO}_{2}$ substrate. Ethoxides, in the presence of gas phase molecular oxygen, then inject two electrons into the excited semiconductor. One of these two electrons may not necessarily be into the valence band (hole trapping) since the radical intermediate (not shown in scheme 1), $\mathrm{CH}_{3} \mathrm{CH}^{*} \mathrm{O}(\mathrm{a})$, has enough energy to directly transfer one electron into the conduction band (current doubling mechanism $[57,58]$ ). This reaction occurs mainly in the presence of gas phase molecular oxygen as they trap electrons from the conduction band. The rate of this reaction decreases with increasing oxygen pressure (negative reaction order). This is because a much faster second channel opens up and this is related to the $\mathrm{C}-\mathrm{C}$ bond dissociation reaction that occurs via a dioxyintermediate, as indicated in brackets in scheme 1. There are sporadic evidences of such an intermediate, one of them from acetone as observed by HREELS [59] and one from formaldehyde as observed by IR [60] over metal oxides. The result of this reaction is the ejection of one methyl radical in the gas phase and the formation of formate species; indicated by an arrow with a rate constant $\mathrm{k}_{3}$. It is also possible that formates are directly formed without the acetaldehyde route as depicted in scheme 1 by $\mathrm{k}_{2}$.

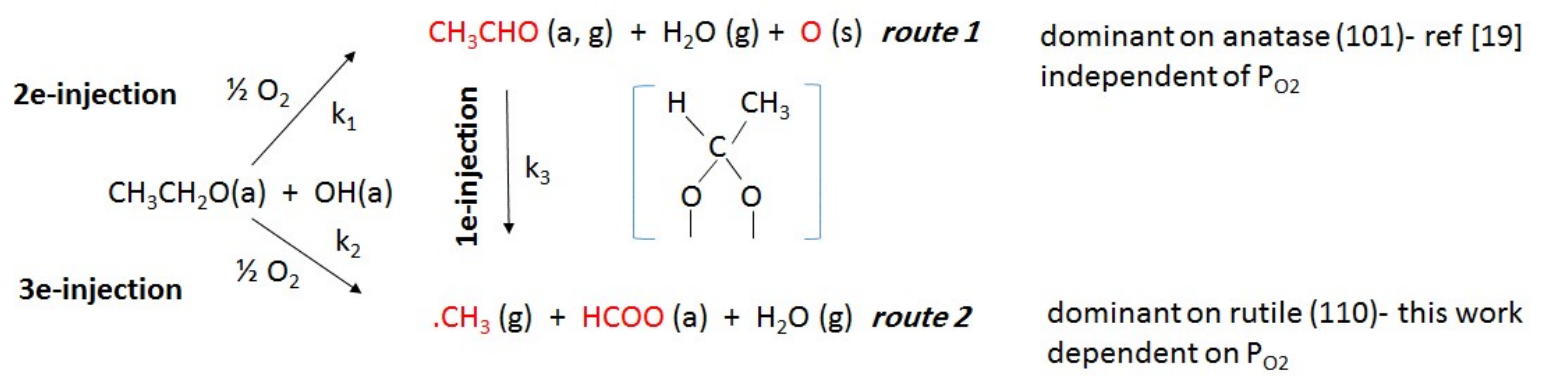

Scheme 1.

Schematic representation of the first step of the reaction network for ethanol photoreaction over $\mathrm{TiO}_{2}$ anatase and rutile single crystal. $k_{1}, k_{2}$ and $k_{3}$ are the reaction rate constants. 


\section{Conclusions}

Photocatalytic reactions of ethanol over rutile $\mathrm{TiO}_{2}(110)$ in the presence of $\mathrm{O}_{2}$, studied by scanning tunneling microscopy and X-ray Photoelectron Spectroscopy, shows mainly two species with their relative density being a function of both time and $\mathrm{P}_{\mathrm{O} 2}$. Initially the surface is covered by ethoxides, at $300 \mathrm{~K}$, which are converted, upon UV exposure, to acetaldehyde at low $\mathrm{P}_{\mathrm{O} 2}$ then to $\mathrm{CH}_{3}$ radicals at high $\mathrm{P}_{\mathrm{O} 2}$ (both products are monitored by mass spectrometry). At high $\mathrm{P}_{\mathrm{O} 2}$ pressures stable features attributed to formate species (monitored by STM and identified by their XPS C1s line at $289.7 \mathrm{eV}$ ), are formed. To further validate the assignment of formate species, formic acid was dosed on the surface and gave similar structures $(6 \AA$ apart along the [001] direction and with height of ca. $1 \AA$ ) to the ones observed after the photo-oxidation of ethoxides. This indicates that $\mathrm{O}_{2}$ partial pressure has a direct impact on $\mathrm{C}$ $\mathrm{C}$ bond cleavage, resulting in a shift of reaction selectivity of gas phase products from acetaldehyde (dehydrogenation) to methyl radicals (C-C bond dissociation) with increasing pressure. The profile of the methyl radical species in the gas phase correlates with that of the build-up formate moieties giving further evidence of their common origin. Two photoreaction cross-sections for $\mathrm{CH}_{3}$ radicals formation were extracted, one at low $\mathrm{P}_{\mathrm{O} 2}$ close to $10^{-19} \mathrm{~cm}^{2}$ which increases to ca. $10^{-17} \mathrm{~cm}^{2}$ at $3 \times 10^{-7}$ mbar (table 1). The work indicates that the surface of $\mathrm{TiO}_{2}(110)$ rutile single crystal behaves differently form that of $\mathrm{TiO}_{2}(101)$ anatase [19] in the photoreaction of ethanol (and probably other oxygen containing hydrocarbons) by switching the reaction products from dehydrogenation to $\mathrm{C}-\mathrm{C}$ bond dissociation.

\section{Acknowledgments}

GT is supported by the European Research Council Advanced Grant EnergySurf and the Royal Society through a Wolson Merit Award. 


\section{References}

[1] A. Fujishma, K. Honda, Electrochemical Photolysis of Water at a Semiconductor Electrode, Nature. 238 (1972) 37-38.

[2] T. Ohno, K. Sarukawa, M. Matsumura, Photocatalytic Activities of Pure Rutile Particles Isolated from $\mathrm{TiO}_{2}$ Powder by Dissolving the Anatase Component in HF Solution, J. Phys. Chem. B. 105 (2001) 2417-2420

[3] S.-J. Kim, H.-G. Lee, S.-J. Kim, J.-K. Lee, E.G. Lee, Photoredox Properties of Ultrafine Rutile $\mathrm{TiO}_{2}$ Acicular powder in aqueous 4-Chlorophenol, $\mathrm{Cu}$-EDTA and $\mathrm{Pb}$-EDTA solutions, Appl. Catal., A. 242 (2003) 89-99

[4] A.K. Wahab, S. Ould-Chikh, K. Meyer, H. Idriss, On the "possible" synergism of the different phases of $\mathrm{TiO}_{2}$ in photo-catalysis for hydrogen production, J. Catal. 352 (2017) 657-671

[5] T. Shirasawa, W. Voegeli, E. Arakawa, T. Takahashi, T. Matsushita, Structural Change of the Rutile- $\mathrm{TiO}_{2}(110)$ Surface During the Photoinduced Wettability Conversion, J. Phys. Chem. C. 120 (2016) 29107-29115

[6] R. Lindsay, A. Wander, A. Ernst, B. Montanari, G. Thornton, N.M. Harrison, Revisiting the Surface Structure of $\mathrm{TiO}_{2}(110)$ : A Quantitative low-Energy Electron Diffraction Study, Phys. Rev. Lett. 94 (2005) 246102-4

[7] G. Charlton, P.B. Howes, C.L. Nicklin, P. Steadman, J.S.G. Taylor, C.A. Muryn, et al., Relaxation of $\mathrm{TiO}_{2}(110)-(1 \times 1)$ Using Surface X-Ray Diffraction, Phys. Rev. Lett. 78 (1997) 495-498

[8] J. Schneider, M. Matsuoka, M. Takeuchi, J. Zhang, Y. Horiuchi, M. Anpo, et al., Understanding $\mathrm{TiO}_{2}$ Photocatalysis: Mechanisms and Materials, Chem. Rev. 114 (2014) 9919-9986

[9] M.A. Nadeem, I. Majeed, G.I.N. Waterhouse, H. Idriss, Study of ethanol reactions on $\mathrm{H}_{2}$ reduced $\mathrm{Au} / \mathrm{TiO}_{2}$ anatase and rutile: effect of metal loading on reaction selectivity, Catal. Struct. React. 1 (2015) 61-70

[10] Y.Z. Yang, C.H. Chang, H. Idriss, Photo-catalytic production of hydrogen form ethanol over $\mathrm{M} / \mathrm{TiO}_{2}$ catalysts (M= Pd, Pt or Rh), App. Cata. B: Env. 67 (2006) 217-222

[11] J.M. Coronado, S. Kataoka, I. Tejedor-Tejedor, M.A. Anderson, Dynamic phenomena during the photocatalytic oxidation of ethanol and acetone over nanocrystalline $\mathrm{TiO}_{2}$ : simultaneous FTIR analysis of gas and surface species, J. Catal. 219 (2003) 219-230

[12] Z. Yu, S. Chuang, In situ IR study of adsorbed species and photogenerated electrons during photocatalytic oxidation of ethanol on $\mathrm{TiO}_{2}$, J. Catal. 246 (2007) 118-126

[13] Z.H.N. Al-Azri, W.-T. Chen, A. Chan, V. Jovic, T. Ina, H. Idriss, et al., The roles of metal co-catalysts and reaction media in photocatalytic hydrogen production: Performance evaluation of $\mathrm{M} / \mathrm{TiO}_{2}$ photocatalysts $(\mathrm{M}=\mathrm{Pd}, \mathrm{Pt}, \mathrm{Au})$ in different alcohol-water mixtures, $\mathrm{J}$. Catal. 329 (2015) 355-367

[14] K.S. Kim, M.A. Barteau, Reactions of aliphatic alcohols on the $\{011\}$-facetted $\mathrm{TiO}_{2}(001)$ surface, J. Mol. Catal. 63 (1990) 1-15.

[15] K.S. Kim, M.A. Barteau, Reactions of Methanol on $\mathrm{TiO}_{2}(001)$ single crystal surfaces, Surf. Sci. 223 (1989) 13-32.

[16] C.L. Pang, R. Lindsay, G. Thornton, Structure of clean and adsorbate-covered single-crystal rutile $\mathrm{TiO}_{2}$ surfaces, Chem. Rev. 113 (2013) 3887-3948

[17] G.S. Herman, Z. Dohnálek, N. Ruzycki, Experimental Investigation of the Interaction of Water and Methanol with Anatase- $\mathrm{TiO}_{2}$ (101), J. Phys. Chem. B. 107 (2003) 2788-2795

[18] C. Xu, W. Yang, Q. Guo, D. Dai, M. Chen, Molecular hydrogen formation from photocatalysis of methanol on anatase- $\mathrm{TiO}_{2}(101)$, J. Am. Chem. Soc. 136 (2014) 602-605

[19] K. Katsiev, G. Harrison, H. Alghamdi, Y. Alsalik, A. Wilson, G. Thornton and H. Idriss, Mechanism of Ethanol Photooxidation on Single-Crystal Anatase $\mathrm{TiO}_{2}(101)$, J. Phys. Chem. C. 121 (2017) 2940-2950 
[20] J.Ø. Hansen, P. Huo, U. Martinez, E. Lira, Y.Y. Wei, Direct Evidence for Ethanol Dissociation on Rutile $\quad \mathrm{TiO}_{2}$ (110), Phys. Rev. Lett. 107 (2011) 136102-136104

[21] C.P. León, K. Sagisaka, D. Fujita, L. Han, Ethanol adsorption on rutile $\mathrm{TiO}_{2}(110)$, RSC Adv. 4 (2014) 8550-8558

[22] J.Ø. Hansen, R. Bebensee, U. Martinez, Unravelling Site-Specific Photo-Reactions of Ethanol on Rutile $\mathrm{TiO}_{2}$ (110), Sci. Rep. 6 (2016) 21990

[23] P.M. Jayaweera, E.L. Quah, H. Idriss, Photoreaction of Ethanol on $\mathrm{TiO}_{2}(110)$ Single-Crystal Surface, J. Phys. Chem. C. 111 (2007) 1764-1769

[24] L. Gamble, L.S. Jung, C.T. Campbell, Decomposition and protonation of surface ethoxys on $\mathrm{TiO}_{2}$ (110), Surf. Sci. 348 (1996) 1-16.

[25] Y.K. Kim, B.D. Kay, J.M. White, Z. Dohnálek, Alcohol Chemistry on Rutile $\mathrm{TiO}_{2}(110)$ : The influence of Alkyl Substituents on Reactivity and Selectivity, J. Phys. Chem. C. 111 (2007) 18236-18242

[26] U. Martinez, J.Ø. Hansen, E. Lira, H.H. Kristoffersen, P. Huo, R. Bechstein, et al., Reduced Step Edges on Rutile $\mathrm{TiO}_{2}(110)$ as Competing Defects to Oxygen Vacancies on the Terraces and Reactive Sites for Ethanol Dissociation, Phys. Rev. Lett. 109 (2012) 155501-155505

[27] C.A. Walenta, S.L. Kollmannsberger, J. Kiermaier, A. Winbauer, M. Tschurl, U. Heiz, Ethanol photocatalysis on rutile $\mathrm{TiO}_{2}(110)$ : the role of defects and water, Phys. Chem. Chem. Phys. 17 (2015) 22809-22814

[28] Z. Ma, Q. Guo, X. Mao, Z. Ren, X. Wang, C. Xu, et al., Photocatalytic Dissociation of Ethanol on $\mathrm{TiO}_{2}$ (110) by Near-Band-Gap Excitation, J. Phys. Chem. C. 117 (2013) 1033610344

[29] A.M. Nadeem, J. Muir, K.A. Connelly, Ethanol photo-oxidation on a rutile $\mathrm{TiO}_{2}(110)$ single crystal surface, Phys. Chem. Chem. Phys. 13 (2011) 7637-7637

[30] E. Farfan-Arribas, R.J. Madix, Role of defects in the adsorption of aliphatic alcohols on the $\mathrm{TiO}_{2}$ (110) surface, J. Phys. Chem. B. 106 (2002) 10680-10692

[31] S. Kundu, A.B. Vidal, M.A. Nadeem, Ethanol Photoreaction on RuOx/Ru-Modified $\mathrm{TiO}_{2}(110)$, J. Phys. Chem. C. 117 (2013) 11149-11158

[32] J.N. Muir, Y. Choi, H. Idriss, Computational study of ethanol adsorption and reaction over rutile $\mathrm{TiO}_{2}(110)$ surfaces, Phys. Chem. Chem. Phys. 14 (2012) 11910-11919

[33] M.D. Kershis, M.G. White, Photooxidation of ethanol and 2-propanol on $\mathrm{TiO}_{2}(110)$ : evidence for methyl radical ejection, Phys. Chem. Chem. Phys. 15 (2013) 17976-17982

[34] R.T. Zehr, M.A. Henderson, Acetaldehyde photochemistry on $\mathrm{TiO}_{2}(110)$, Surf. Sci. 602 (2008) 2238-2249

[35] M.A. Henderson, Photooxidation of Acetone on $\mathrm{TiO}_{2}(110)$ : Conversion to Acetate via Methyl Radical Ejection, J. Phys. Chem. B. 109 (2005) 12062-12070

[36] Y. Nosaka, K. Koenuma, K. Ushida, A. Kira, Reaction mechanism of the decomposition of acetic acid on illuminated $\mathrm{TiO} 2$ powder studied by means of in situ electron spin resonance measurements, Langmuir. 12 (1996) 736-738

[37] G.L. Chiarello, D. Ferri, E. Selli, Effect of the $\mathrm{CH}_{3} \mathrm{OH} / \mathrm{H}_{2} \mathrm{O}$ ratio on the mechanism of the gas-phase photocatalytic reforming of methanol on noble metal-modified $\mathrm{TiO}_{2}$, J. Catal. 280 (2011) 168-177

[38] C.R. López, E.P. Melián, J.A.O. Méndez, D.E. Santiago, J.M.D. Rodríguez, O.G. Díaz, Comparative study of alcohols as sacrificial agents in $\mathrm{H}_{2}$ production by heterogeneous photocatalysis using $\mathrm{Pt} / \mathrm{TiO}_{2}$ catalysts, J. Photochem. Photobiol. C: Photochem. Rev. 312 (2015) 45-54

[39] G.R. Bamwenda, S. Tsubota, T. Nakamura, M. Haruta, Photoassisted hydrogen production from a water-ethanol solution: a comparison of activities of $\mathrm{Au}-\mathrm{TiO}_{2}$ and $\mathrm{Pt}-\mathrm{TiO}_{2}$, J. Photochem. Photobiol. C: Photochem. Rev. 89 (1995) 177-189

[40] H. Onishi, T. Aruga, Y. Iwasawa, Switchover of Reaction Paths in the Catalytic Decomposition of Formic Acid on $\mathrm{TiO}_{2}$ (110) Surface, J. Catal. 146 (1994) 557-567

[41] D.C. Grinter, T. Woolcot, C.-L. Pang, G. Thornton, Ordered Carboxylates on $\mathrm{TiO}_{2}(110)$ Formed at Aqueous Interfaces, J. Phys. Chem. Lett. 5 (2014) 4265-4269 
[42] M. Aizawa, Y. Morikawa, Y. Namai, H. Morikawa, Y. Iwasawa, Oxygen Vacancy Promoting Catalytic Dehydration of Formic Acid on $\mathrm{TiO}_{2}(110)$ by in Situ Scanning Tunneling Microscopic Observation, J. Phys. Chem. B. 109 (2005) 18831-18838

[43] M. Bowker, P. Stone, R. Bennett, N. Perkins, Formic acid adsorption and decomposition on $\mathrm{TiO}_{2}(110)$ and on $\mathrm{Pd} / \mathrm{TiO}_{2}(110)$ model catalysts, Surf. Sci. 511 (2002) 435-448

[44] A. Gutuerrez-Sosa, P. Martinez-Escolano, H. Raza, R. Lindsay, P.L. Wincott, G. Thornton, Orientation of carboxylates on $\mathrm{TiO}_{2}(110)$, Surf. Sci. 471 (2000) 163-169

[45] A. Mattsson, S. Hu, K. Hermansson, L. Österlund, Adsorption of formic acid on rutile $\mathrm{TiO}_{2}(110)$ revisited: An infrared reflection-absorption spectroscopy and density functional theory study, J. Chem. Phys. 140 (2014) 034705-034713.

[46] B.E. Hayden, A. King, M.A. Newton, Fourier Transform Reflection-Absorption IR Spectroscopy Study of Formate Adsorption on $\mathrm{TiO}_{2}$ (110), J. Phys. Chem. B. 103 (1999) 203-208

[47] P. Käckell, K. Terakura, First-principle analysis of the dissociative adsorption of formic acid on rutile $\mathrm{TiO}_{2}$ (110), Appli. Surf. Sci. 166 (2000) 370-375

[48] P. Käckell, K. Terakura, Dissociative adsorption of formic acid and diffusion of formate on the TiO2(110) surface: the role of hydrogen, Surf. Sci. 461 (2000) 191-198

[49] H. Hussain, X. Torrelles, G. Cabailh, P. Rajput, R. Lindsay, O. Bikondoa, et al., Quantitative Structure of an Acetate Dye Molecule Analogue at the $\mathrm{TiO}_{2}-$ Acetic Acid Interface, J. Phys. Chem. C. 120 (2016) 7586-7590

[50] P. Huo, J.Ø. Hansen, U. Martinez, E. Lira, R. Streber, Y. Wei, et al., Ethanol Diffusion on Rutile $\mathrm{TiO}_{2}(110)$ Mediated by H Adatoms, J. Phys. Chem. Lett. 3 (2012) 283-288. doi:10.1021/jz201616z.

[51] R. Atkinson, Kinetics and mechanisms of the gas-phase reactions of the hydroxyl radical with organic compounds under atmospheric conditions, Chem. Rev. 86 (1986) 69-201

[52] G.J. Fleming, K. Adib, J.A. Rodriguez, M.A. Barteau, H. Idriss, Proline adsorption on TiO2(110) single crystal surface: A study by high resolution photoelectron spectroscopy, Surface Science (2007) 5726-5731

[53] Y. K. Gao, F. Träger, C. Wöll, H. Idriss, Glycine Adsorption and Photo-reaction over $\mathrm{ZnO}(000 \overline{1})$, Surface Science, 624, 112-117

[54] E.L. Quah, J.N. Wilson, H. Idriss, Photoreaction of the Rutile $\mathrm{TiO}_{2}(011)$ SingleCrystal Surface: Reaction with Acetic Acid, Langmuir, 2010, 26(9), 6411-6417

[55] Q. Guo, E.M. Williams, The Effect of Adsorbate-Adsorbate Interaction on the Structure of Chemisorbed Overlayers on $\mathrm{TiO}_{2}$ (110), Surface Science, 433-435, (1999), 322-326

[56] K-I Fukui, Y. Iwasawa, Fluctuation of Acetate Ion in the (2 x 1)-acetate overlayer on $\mathrm{TiO}_{2}(110)-(1 \times 1)$ oberved by noncontact atomic force microscopy, Surface Science Letters, 464 (2000) L719-L726

[57] A. Yamakata, T.-A. Ishibashi, H. Onishi, Electron- and Hole-Capture Reactions on Pt/ $/ \mathrm{TiO}_{2}$ Photocatalyst Exposed to Methanol Vapor Studied with Time-Resolved Infrared Absorption Spectroscopy, J. Phys. Chem. B. 106 (2002) 9122-9125

[58] O.I. Micic, Y.N. Zhang, K.R. Cromack, A.D. Trifunac, M.C. Thurnauer, Photoinduced hole transfer from $\mathrm{TiO}_{2}$ to methanol molecules in aqueous-solution studied by electronparamagnetic resonance, J. Phys. Chem. 97 (1993) 13284-13288.

[59] M.A. Henderson, Acetone Chemistry on Oxidized and Reduced $\mathrm{TiO}_{2}(110)$, J. Phys. Chem. B. 108 (2004) 18932-18941

[60] H. Idriss, J.P. Hindermann, R. Kieffer, A. Kiennemann, A. Vallet, C. Chauvin, et al., Characterization of dioxymethylene species over cu-zn catalysts, J. Mol. Catal. 42 (1987) 205-213

\section{Supporting Information}



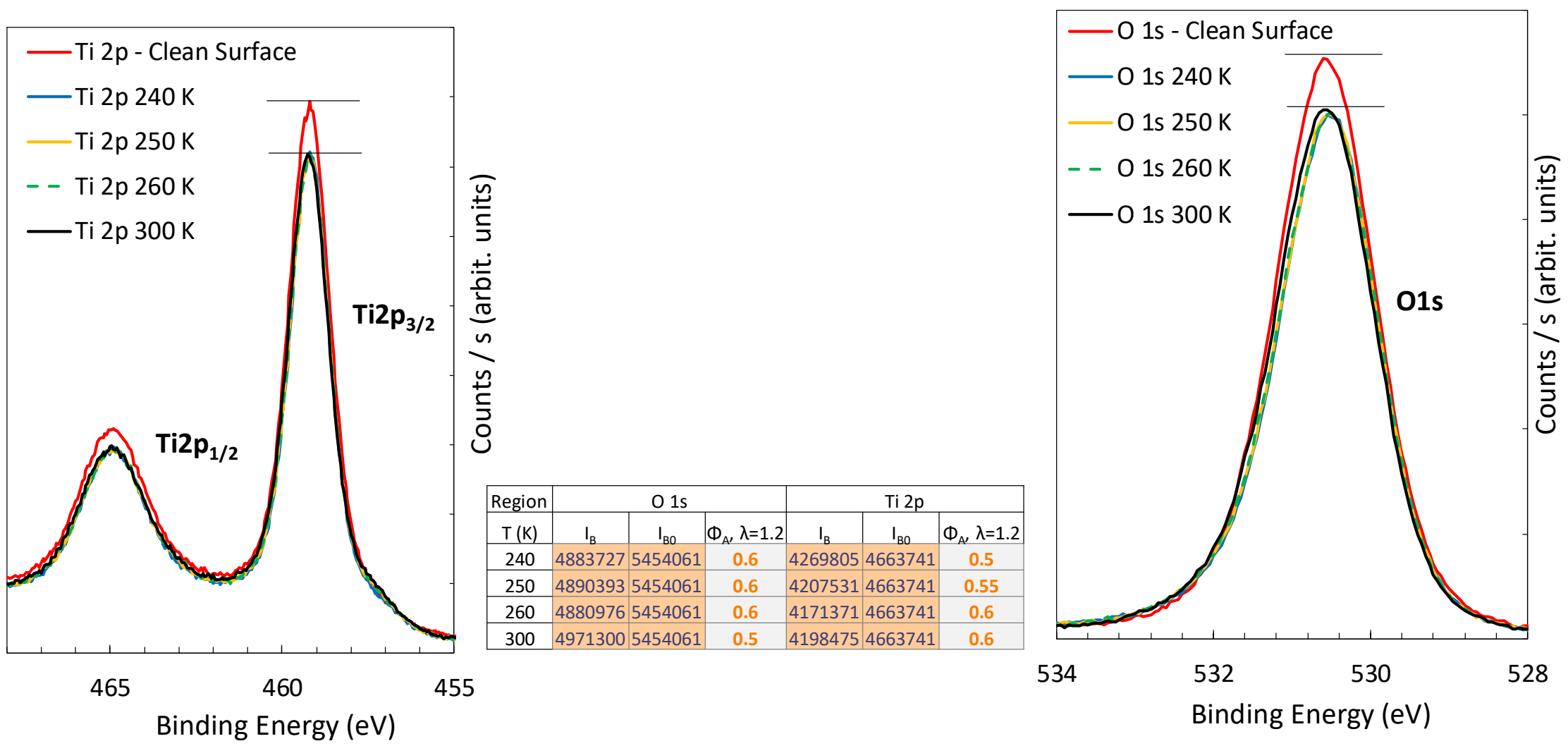

Figure $\mathrm{S} 1$

XPS Ti2p and O1s before and after ethanol adsorption at $240 \mathrm{~K}$, followed by heating at the indicated temperatures. The table gives the raw signals from which the surface coverage was computes, taking an escape depth $(\lambda)$ of $1.2 \mathrm{~nm}$. $\phi$ stands for surface coverage with respect to Ti cations and oxygen anions. 

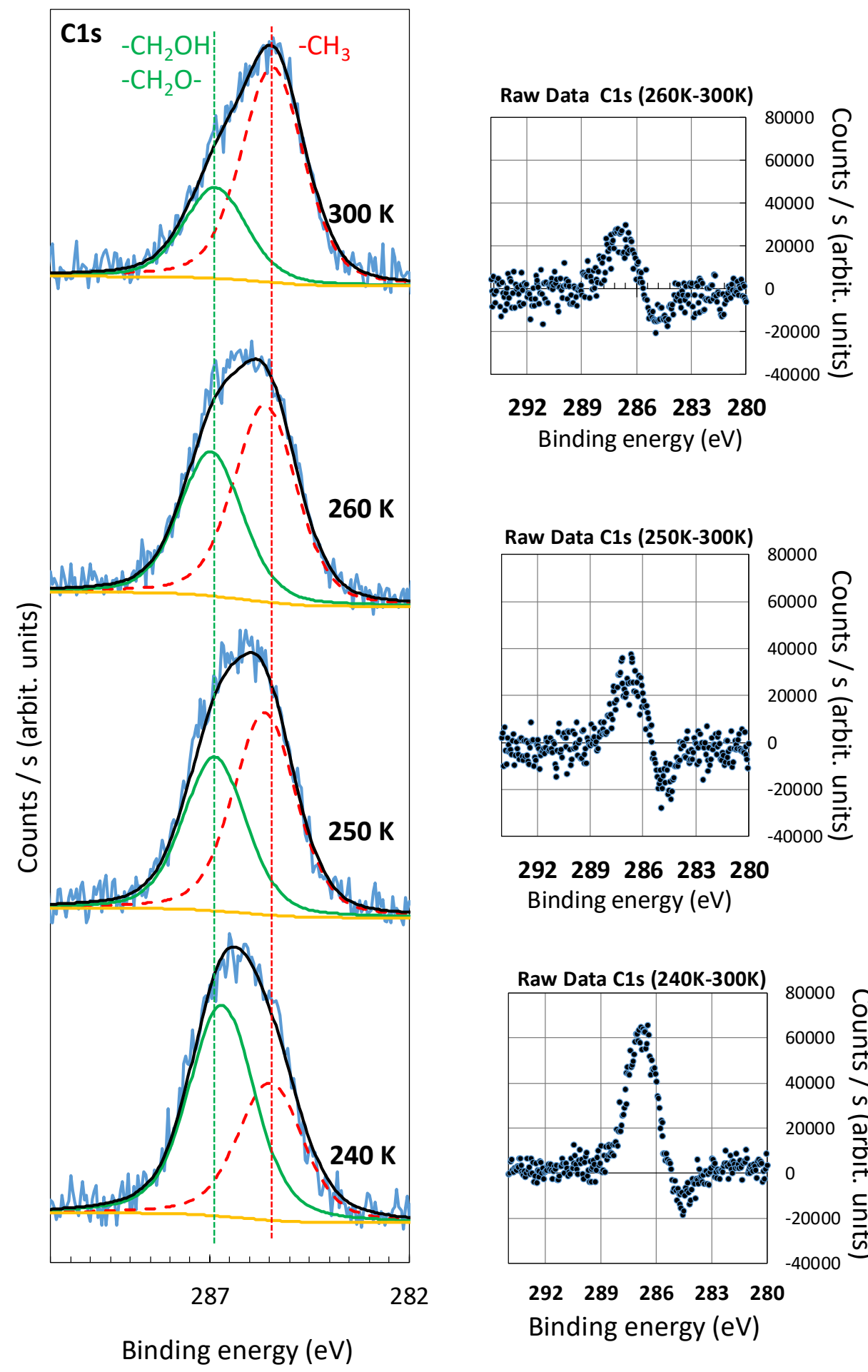

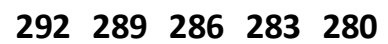

Binding energy $(\mathrm{eV})$

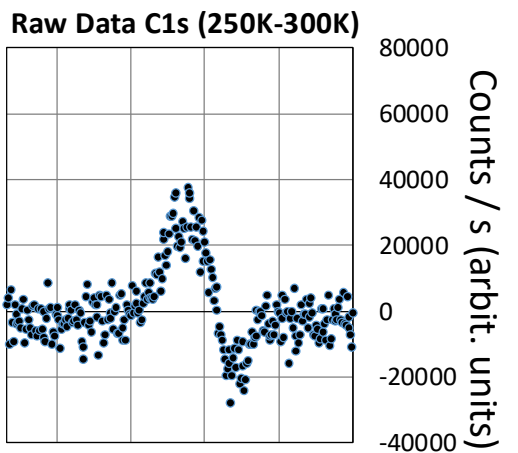

292289286283280

Binding energy (eV)

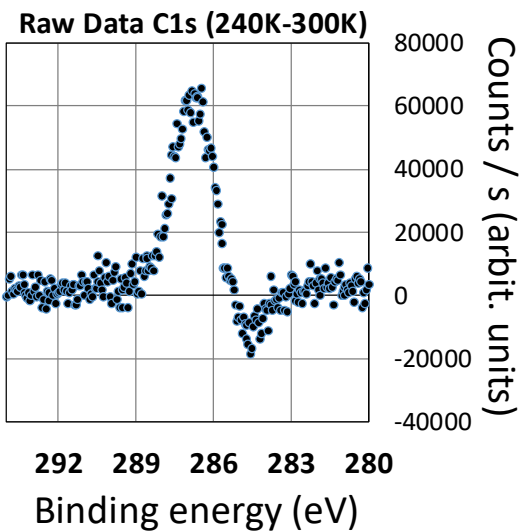

Figure S2

XPS C1s before and after ethanol adsorption at $240 \mathrm{~K}$, followed by heating at the indicated temperatures. The right hand side shows the difference $\mathrm{C} 1 \mathrm{~s}$ spectra between that obtained at $240 \mathrm{~K}$ and the ones heated at the indicated temperatures. The difference spectra indicate ethanol contribution into the raw signal. 


\section{Clean surface - before ethanol adsorption}
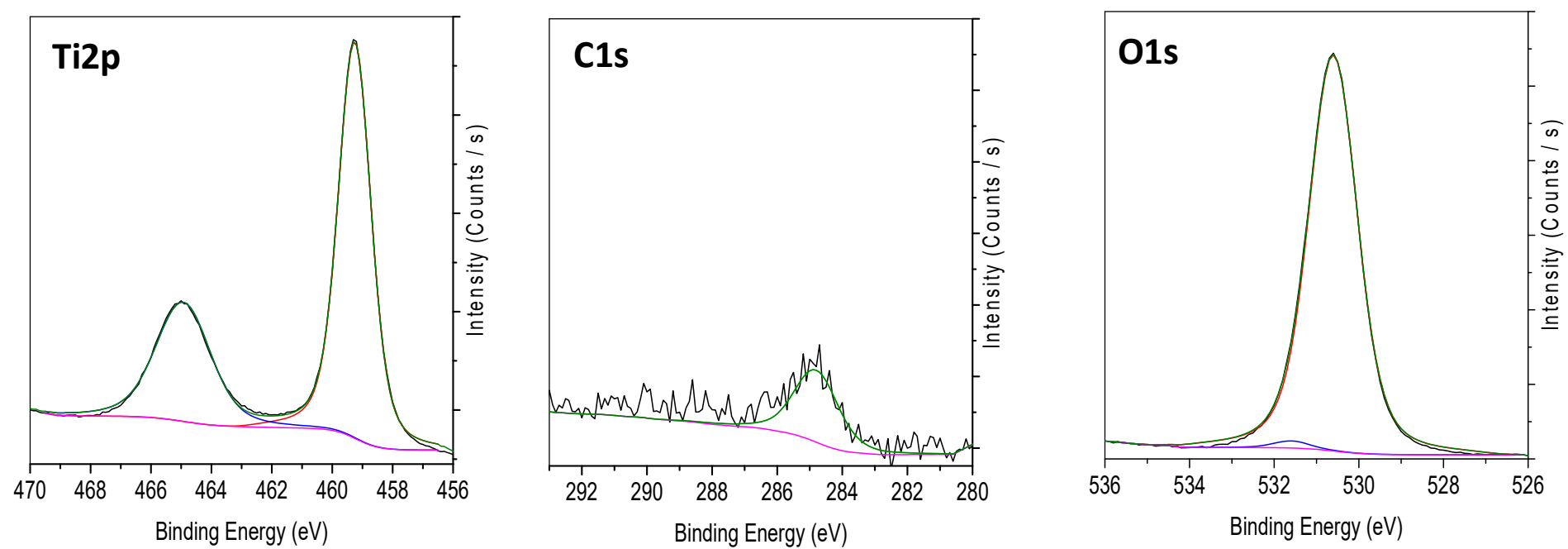

\begin{tabular}{|c|c|c|c|c|}
\hline Element & RSF & Total Peak Area & Corrected P.A. & At $\%$ \\
\hline $\mathrm{Ti}$ & 1.798 & 18207660.44 & 10126618.71 & $29.6 \%$ \\
\hline 0 & 0.711 & 17047923.93 & 23977389.49 & $70.0 \%$ \\
\hline $\mathrm{C}$ & 0.296 & 37922.06 & 128115.0676 & $0.4 \%$ \\
\hline \multicolumn{3}{|c|}{ Total } & 34232123.27 & $100 \%$ \\
\hline
\end{tabular}

\begin{tabular}{|c|c|c|c|}
\hline \multicolumn{4}{|c|}{ Clean surface } \\
\hline Name & Peak BE & Height CPS & Area CPS.eV \\
\hline C & 284.80 & 20130.93 & 37922 \\
\hline
\end{tabular}

Figure S3

XPS Ti2p, $\mathrm{C} 1 \mathrm{~s}$ and $\mathrm{O} 1 \mathrm{~s}$ of the clean $\mathrm{TiO}_{2}(110)$ rutile single crystal before adsorption. The tables below indicate the raw data and the atomic $\%$ of each line. RSF stands for Relative Sensitivity Factors; CPS stands for Counts Per Second. 


\section{Ethanol adsorption, surface saturation at 300K}
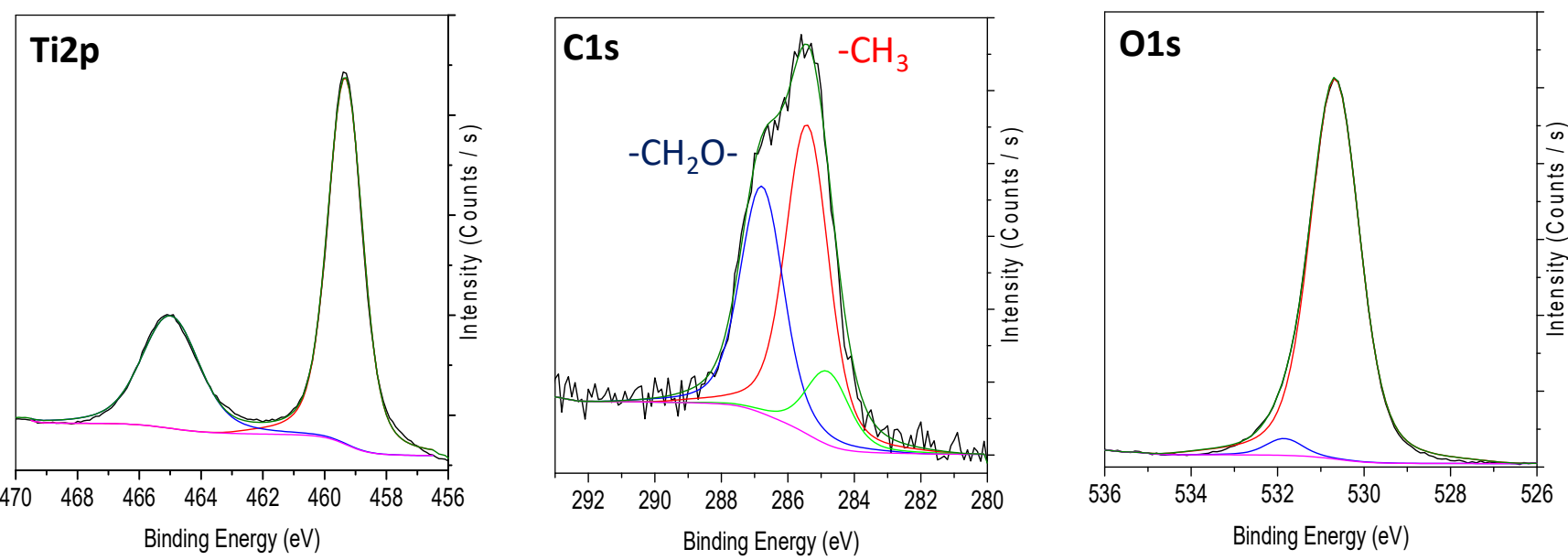

\begin{tabular}{|c|c|c|c|c|}
\hline Element & RSF & Total Peak Area & Corrected P.A. & At \% \\
\hline $\mathrm{Ti}$ & 1.798 & 17239760.99 & 9588298.66 & $28.5 \%$ \\
\hline $\mathrm{O}$ & 0.711 & 16413049.1 & 23084457.24 & $68.5 \%$ \\
\hline $\mathrm{C}$ & 0.296 & 300340.81 & 1014664.899 & $3.0 \%$ \\
\hline \multicolumn{6}{|c|}{ Total } & 33687420.8 & $100 \%$ \\
\hline
\end{tabular}

\begin{tabular}{|c|c|c|c|c|}
\hline \multicolumn{5}{|c|}{$\mathrm{EtOH}$ on $\mathrm{TiO}_{2}$} \\
\hline Name & Peak BE & Height CPS & Area CPS.eV & / Concentration \\
\hline $\mathrm{C}-\mathrm{C}$ & 284.8 & 20130.93 & 36129.5 & $12 \%$ \\
\hline $\mathrm{CH}_{3}$ & 285.4 & 84915.98 & 152418.29 & $51 \%$ \\
\hline$-\mathrm{CH}_{2} \mathrm{O}-$ & 286.8 & 62282.29 & 111793.02 & $37 \%$ \\
\hline \multicolumn{3}{|c|}{ Total } & 300341 & $100 \%$ \\
\hline
\end{tabular}

\begin{tabular}{|c|c|c|c|c|c|c|}
\hline Region & \multicolumn{3}{|c|}{$01 \mathrm{~s}$} & \multicolumn{3}{c|}{ Ti 2p } \\
\hline Experiment & $\mathrm{I}_{B}$ & $\mathrm{I}_{\mathrm{B} 0}$ & $\Phi_{\mathrm{A}^{\prime}} \lambda=1.2$ & $\mathrm{I}_{B}$ & $\mathrm{I}_{\mathrm{B} 0}$ & $\Phi_{\mathrm{A}^{\prime}} \lambda=1.2$ \\
\hline After Dosing EtOH & 10033442 & 10622071 & 0.325 & 9585814 & 10485392 & 0.504 \\
\hline
\end{tabular}

Figure S4

XPS Ti2p, $\mathrm{C} 1 \mathrm{~s}$ and $\mathrm{O} 1 \mathrm{~s}$ of ethanol dosed $\mathrm{TiO}_{2}(110)$ rutile single crystal at $300 \mathrm{~K}$ (saturation coverage). The tables below indicate the raw data and the atomic $\%$ of each line. RSF stands for Relative Sensitivity Factors; CPS stands for Counts Per Second. $\phi$ stands for surface coverage with respect to Ti cations and oxygen anions, taking an escape depth $(\lambda)$ of $1.2 \mathrm{~nm}$. 


\section{Surface adsorbates after photo-catalytic reaction}

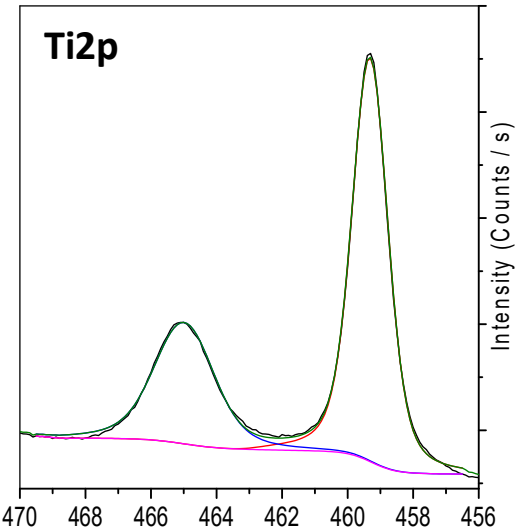

Binding Energy (eV)
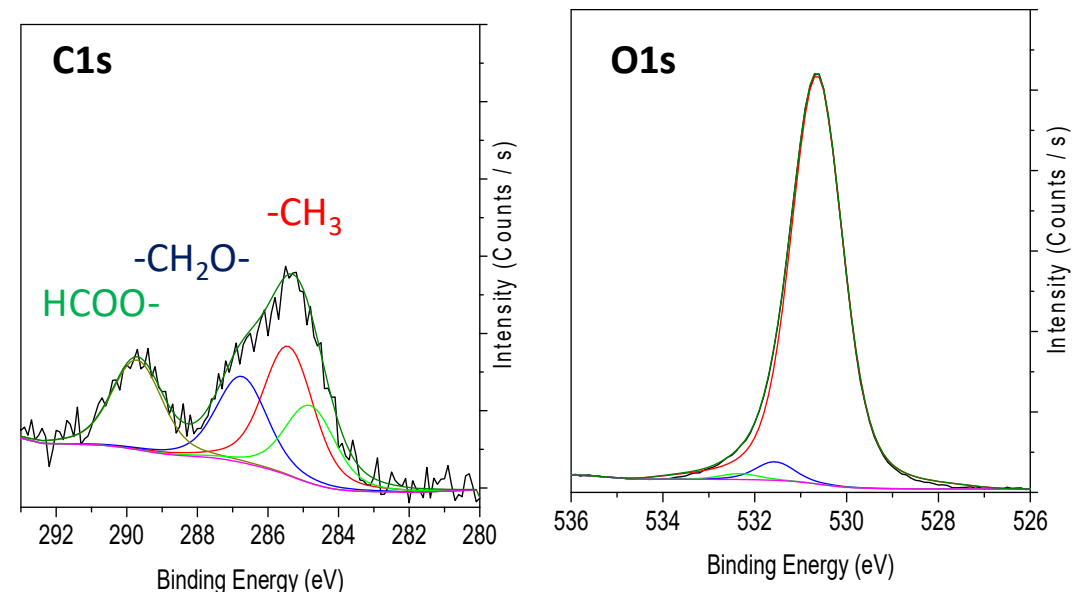

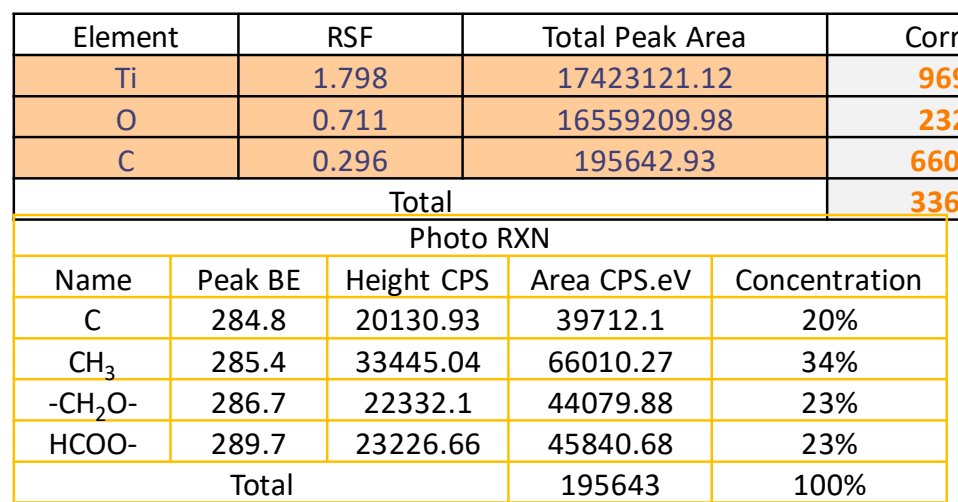

\begin{tabular}{|c|c|}
\hline Corrected P.A. & At $\%$ \\
\hline 9690278.71 & $28.8 \%$ \\
\hline 23290028.1 & $69.2 \%$ \\
\hline 660955.8446 & $2.0 \%$ \\
\hline 33641262.66 & $100 \%$ \\
\hline
\end{tabular}

41262.66

\begin{tabular}{|c|c|c|c|c|c|c|}
\hline Region & \multicolumn{3}{|c|}{ O 1s } & \multicolumn{3}{c|}{ Ti 2p } \\
\hline Experiment & $\mathrm{I}_{B}$ & $\mathrm{I}_{\mathrm{B} 0}$ & $\Phi_{\mathrm{A}}, \lambda=1.2$ & $\mathrm{I}_{\mathrm{B}}$ & $\mathrm{I}_{\mathrm{B} 0}$ & $\Phi_{\mathrm{A}^{\prime}} \lambda=1.2$ \\
\hline & 1016183 & 1062207 & & & 1048539 & \\
After Photo RXN & 2 & 1 & 0.254 & 9902661 & 2 & 0.326 \\
\hline
\end{tabular}

Figure S5

XPS Ti2p, $\mathrm{C} 1 \mathrm{~s}$ and $\mathrm{O} 1 \mathrm{~s}$ of ethanol dosed $\mathrm{TiO}_{2}(110)$ rutile single crystal at $300 \mathrm{~K}$ (saturation coverage) that was exposed to UV light for 30 minutes with a flux equal to ca. $10^{16}$ photons $\mathrm{cm}^{-2} \mathrm{~s}^{-1}$ in the $320-400 \mathrm{~nm}$ range. The tables below indicate the raw data and the atomic $\%$ of each line. RSF stands for Relative Sensitivity Factors; CPS stands for Counts Per Second. $\phi$ stands for surface coverage with respect to Ti cations and oxygen anions, taking an escape depth $(\lambda)$ of $1.2 \mathrm{~nm}$. 
